ISSN: 0212-0267

DOI: http://dx.doi.org/IO.I420I/hedu20I837223255

\title{
LA MOVILIZACIÓN Y LA PROTESTA ESTUDIANTIL EN EL TARDOFRANQUISMO Y LA DEMOCRACIA
}

\section{Mobilization and student protest in late francoism and democracy}

Eduardo González CAlleja

Universidad Carlos III de Madrid

Correo-e: edgcalle@hum.uczm.es

Recepción: 20 de septiembre de 20I7. Envío a informantes: 8 de octubre de 2017 Aceptación definitiva: is de diciembre de 2017

REsumen: El presente artículo trata de analizar las protestas estudiantiles producidas en España desde los años setenta hasta la actualidad. Tras un recorrido sumario sobre los antecedentes históricos de la movilización escolar desde el siglo XIX, se estudian los elementos de contexto, oportunidad y organización que confluyeron en el desencadenamiento, expansión y declive del último gran ciclo de protestas universitarias contra la dictadura que tuvo lugar entre 1968 y 1973. Estos factores son comparados con las movilizaciones acaecidas desde la transición democrática, para tratar de explicar las posibles razones de su menor duración e impacto social y político.

Palabras clave: Universidad; movilización estudiantil; conflicto político; juventud; España; siglos xx y xxI.

AвSTRACT: This article tries to analyze the student protests produced in Spain from the seventies to the present. After a summary tour of the historical background of school mobilization since the igth century, the elements of context, opportunity and organization that converged in the unleashing, expansion and decline of the last great cycle of protests against the dictatorship that took place between 1968 and 1973. These factors are compared with the mobilizations that have occurred since the democratic transition, to try to explain the possible reasons for their shorter duration and lesser social and political impact. 
KEY WORDs: University; student mobilization; political conflict; youth; Spain; $2 \mathrm{O}^{\text {th }}$ and $2 \mathrm{I}^{\text {st }}$ centuries.

\section{L}

OS ESTUDIANTES HAN EJERCIDO EN LAS SOCIEDADES CONTEMPORÁNEAS Una importante función de movilización de la opinión pública. En cierto modo, la conducta estudiantil es anticipatoria de la de los mayores, pero es el descontento social y político el que genera habitualmente el descontento escolar, y no al revés. La protesta escolar presenta un carácter cíclico y frecuentemente discontinuo, porque cada generación de estudiantes deja paso a la siguiente sin que haya tiempo para que se establezca una auténtica articulación intergeneracional. Su difusa identidad, que depende en buena parte de la intensidad de su compromiso en la defensa de sus intereses corporativos frente a las autoridades académicas y políticas, explica las variaciones que experimentan las organizaciones estudiantiles en su dinámica reivindicativa, que combina momentos de fuerte movilización con largos periodos de apatía. El hecho de que la experiencia escolar «normal» sea breve limita la continuidad del movimiento estudiantil, como pudieron constatar los fundadores de la Federación Universitaria Escolar (FUE) durante la República o los delegados de los Sindicatos Democráticos de Estudiantes Universitarios (sDEUs) durante el tránsito de los 60 a los 70. El problema de la transmisión del sentimiento disidente fue una preocupación constante de las fuerzas antifranquistas, que trataron de superar con un incremento de la militancia política y la construcción de una contracultura contestataria capaz de socializar con rapidez a las nuevas hornadas de estudiantes.

El propósito central de este trabajo es dar cuenta de las agitaciones estudiantiles que se desarrollaron en España durante el tardofranquismo y la democracia. En primer lugar, presentaremos los antecedentes históricos desde mediados del siglo XIX a 1965, y a continuación nos detendremos en los factores que confluyeron en el desencadenamiento y reflujo del último gran ciclo de protesta escolar que se desarrolló entre i968 y I973, y en otras coyunturas, más efímeras, de movilización acaecidas desde la transición hasta nuestros días.

\section{Los albores de la protesta estudiantil en España, entre la algarada y la protesta corporativa (1865-1925)}

Las primeras grandes movilizaciones universitarias se remontan a la segunda mitad del siglo xIX. Por aquel entonces, la peculiar situación de subordinación funcional y de autonomía política de la Universidad facilitaba la irrupción de un tipo de protesta desestructurada en forma de motín o algarada estudiantil, motivada por razones de disciplina académica. Este tipo de acciones no tenían un carácter político, se manifestaban en forma de una explosión de violencia incontrolada, estaban dirigidas en general contra el profesorado y quedaban circunscritas al recinto universitario. En el último tercio del siglo xix fue perfilándose una movilización 
corporativa que tenía también un origen académico, pero que estaba vinculada a razones ideológicas, como la defensa de los valores de la democracia, la libertad de expresión o el laicismo, lo que daba un tono de incipiente politización a la protesta. Acostumbraban a iniciarse como movimientos de adhesión al profesorado, y su rápido desarrollo, frecuentemente tumultuario, superaba los límites de las instituciones académicas para convertirse en un problema de orden público que requería la intervención de las autoridades. Este fue el caso de los «sucesos de la Noche de San Daniel» de I865, cuyo origen estuvo en la prohibición ministerial de expresión de ideas contrarias a la Monarquía y al Concordato. La protesta y ulterior sanción a Emilio Castelar dio paso a una dinámica de tumultuaria de creciente amplitud que acabó el Io de abril en la «Noche del Matadero», en la que dos millares de manifestantes libraron duros enfrentamientos con la Guardia Civil Veterana que se saldaron con I4 muertos, 74 heridos y II4 detenidos ${ }^{\mathrm{I}}$. Los alborotos de la «Santa Isabel», acaecidos del 17 al 22 de noviembre de I884, tuvieron también un móvil ideológico y académico, ampliado a continuación a la crítica al régimen de la Restauración: tras la airada reacción de carlistas e integristas al discurso racionalista del catedrático de Historia Universal Miguel Morayta en la inauguración del curso académico I884-1885, los jóvenes liberales y republicanos elevaron una enérgica protesta que fue respondida con un asalto policial al claustro de Noviciado. Los estudiantes hicieron llamamientos a la libertad de cátedra y a la unidad de la «familia escolar», típicos de estos movimientos de defensa de la comunidad universitaria. Aunque no participó más de la cuarta parte de los cerca de I2.000 estudiantes afincados en Madrid, la onda de adhesión escolar fue creciendo hasta afectar a otros distritos universitarios de España y el extranjero ${ }^{2}$.

La participación estudiantil también fue muy nutrida en los enfrentamientos suscitados por la negativa a aceptar las vacaciones concedidas con motivo del anuncio de la boda de la princesa de Asturias con el hijo del dirigente carlista conde de Caserta a inicios de roor. En esta ocasión, la politización de un contencioso de origen académico desembocó los días 8 a I2 de febrero en una serie de manifestaciones tumultuarias, cuya dinámica resultó muy similar a la de los sucesos de i884 y los que acaecerían en los años veinte contra Primo de Rivera ${ }^{3}$. El último gobierno de Sagasta, que llegó al poder al mes siguiente, dio un impulso a la creación de Uniones Escolares como revulsivo profesional frente al avance clerical. Ello no impidió la continuación de los viejos modos de protesta, motivados por

Pordomingo, Isabel y Espantaleón, Antonio: «De San Daniel a San Gil», Historia 16, 53 (septiembre 1980), pp. 29-38 y Rupérez, Paloma: La cuestión universitaria y la Noche de San Daniel, Madrid, EDICUSA, 1975 .

Véanse Pi y Margall, Francisco: Historia de España en el siglo XIX, Barcelona, M. Seguí, I902, vol. vI, pp. 26I-290 y MoraYTA, Miguel: La libertad de la cátedra: Sucesos universitarios de la Santa Isabel, Madrid, Edit. Española-Americana, I9II.

Véanse «Riots in Madrid» (Madrid, I8-2-I90I), en National Archives, Foreign Office, leg. 72/2146 y el informe de la Embajada francesa de I4-II-I9OI, en Archive du Ministère des Affaires Étrangères, Nouvelle Série, I896-1918, Espagne, vol. 2, pp. 15-23, además de GonZález Calleja, Eduardo: Rebelión en las aulas. Movilización y protesta estudiantil en la España contemporánea (I865-2008), Madrid, Alianza, 2009, pp. 78-83. 
sucesos banales, pero de fuerte contenido simbólico, como el abofeteamiento de un estudiante por un comisario de Policía que desembocó en una algarada en la Universidad de Salamanca el i y 2 de abril de 1903, en la que guardias penetraron en los claustros y dispararon, matando a dos estudiantes. A pesar del intento de mediación del rector Unamuno la protesta se extendió hasta el día 7 a otros centros de enseñanza de Valladolid, Valencia, Zaragoza y Madrid, donde en las agitaciones se mezclaron escolares y trabajadores manuales, uno de los cuales resultó muerto.

Según Isaura Varela, a inicios del siglo xx los conflictos estudiantiles más destacados eran los de tipo reivindicativo (léase de orden académico), seguidos de los de solidaridad (defensa del prestigio y singularidad del colectivo escolar frente a las «agresiones» externas de la prensa o la policía), y a mayor distancia los políticos y las faltas disciplinarias, muy frecuentes en la Universidad del siglo xix, pero que a partir de I9I7-I9I8 desaparecieron casi por completo4. El descontento se solía expresar en desórdenes en el interior de los centros, con abandono del aula y el consiguiente castigo. El otro repertorio era el de la manifestación callejera más o menos tumultuaria, con reuniones, nombramiento de una comisión negociadora, manifestaciones, reparto de panfletos o pegada de carteles. La protesta estudiantil era, pues, un hecho muy frecuente en los primeros años del siglo xx, pero en ningún caso la movilización fue general, ni obedeció a razones verdaderamente subversivas. Salvo pequeños grupos de disidentes (fueran carlistas, republicanos o librepensadores de toda laya), y dejando aparte la especialísima situación de Cataluña, la tónica ideológica de la Universidad estaba en sintonía con la extracción social de sus integrantes. Es decir, podía ser más o menos liberal y democrática, pero no cuestionaba la vigencia de un régimen que, a corto plazo, conseguía asimilar profesionalmente, e incluso cooptar políticamente, a la mayoría de los egresados.

A fines de la primera década del siglo se abandonaron progresivamente las viejas fórmulas asociativas de carácter informal y lúdico y se celebraron los primeros congresos escolares de ámbito nacional, como el celebrado en Valencia en 1909, que conllevó la creación de la Federación Nacional Escolar (FNE) en igir. Pero el tema de la libertad de cátedra provocó la división entre estudiantes «neutros» -léase liberales- y estudiantes católicos, que acabaron por separarse del movimiento general y crear en 1920-2I la Federación de Estudiantes Católicos (FEC) bajo los auspicios de Ángel Herrera y El Debates.

La participación legalizada de los estudiantes en la vida universitaria estaba recogida en los estatutos de autonomía promulgados en septiembre de I92I a raíz del Real Decreto de César Silió de 2r de mayo de i9r9. Esta norma obligaba a los estudiantes a constituir Asociaciones Oficiales en cada Facultad, que se articulaban en el organismo central de la Unión Nacional de Estudiantes, a través

4 Varela, Isaura: «Universidad nueva y nuevos estudiantes. El cambio de los universitarios “troyanos" a los de la fue», en Castro, Xavier y Juana, Jesús de (eds.): Mentalidades colectivas e ideoloxías, Orense, Diputación Provincial de Ourense, I991, pp. 238-24I.

Mancebo, María Fernanda: La Universidad de Valencia. De la Monarquía a la República (I9I9-1939), Valencia, Instituto de Cultura Juan Gil-Albert/Universitat de València, 1994, p. 8I. 
del cual podrían intervenir en el gobierno de la Universidad de acuerdo con sus estatutos. Al prohibirse las asociaciones de carácter político y religioso, las entidades escolares abandonaron su carácter meramente recreativo y acentuaron su impronta de defensa corporativa. Desde el curso 1922-23, los grupos católicos trataron de disputar la representatividad estudiantil a los sindicatos profesionales, que se organizaron incluso en los institutos de segunda enseñanza. Las asociaciones laicas luchaban en condiciones de desigualdad con organizaciones confesionales, acusadas de ejercer una especie de «somatenismo estudiantil» contra la libertad de cátedra. La tensión en las aulas aumentó, y estalló en enfrentamientos violentos merced a la instrumentalización de algunos incidentes políticos.

\section{La movilización estudiantil entre dos dictaduras (1925-1968)}

La oposición escolar al general Primo de Rivera constituye la línea divisoria entre el modelo de universitario despreocupado, desmovilizado y conservador y el nuevo universitario rebelde de clase media que prevalecerá hasta los estertores de la dictadura franquista. El movimiento de protesta escolar había heredado las tensiones entre estudiantes liberales y católicos, cuya politización había ido avanzando desde la Primera Guerra Mundial. La «rebelión de las aulas» contra la política educativa del gobierno primorriverista fue encauzada por las asociaciones profesionales acogidas al Decreto de 192I, que tuvieron la virtualidad de ofrecer un instrumento idóneo para las manifestaciones de disenso juvenil. Tras la desaparición de la FNE, la antorcha de la lucha pasó a federaciones escolares de contenido progresista, como la Unión Liberal de Estudiantes (ULE), promovida a fines de i924 como uno de los resortes de contestación política al régimen dictatorial. Pero la ocasión para realizar una verdadera labor rupturista la brindó una cuestión no estrictamente política: el artículo 53 de la Ley de Reforma Universitaria impulsada por el ministro de Instrucción Pública Eduardo Callejo, que protegía la enseñanza privada, en especial la religiosa, equiparándola con la pública en la expedición de títulos académicos. La protesta contra la «Ley Callejo» fue una respuesta de autodefensa de los estudiantes contra la plétora de licenciados en las profesiones liberales. La ULE lanzó un sonado manifiesto el 26 de abril de I925, y el is de mayo, en el transcurso de una serie de huelgas estudiantiles, se produjo el primer gran enfrentamiento del dictador con los escolares, al sancionar a uno de sus dirigentes, el estudiante de agronomía Antonio María Sbert.

La no aprobación gubernativa de los estatutos de la ULE indujo a los estudiantes a revitalizar las Asociaciones Profesionales de cada Facultad, que gozaban de un marco legal para actuar. A fines del curso 1925-1926 se comenzó a dar forma a la Federación Universitaria Escolar (FUE) con un carácter teóricamente profesional. Pero a pesar de declararse aconfesional y apolítica, mantenía una línea de pensamiento liberal y socialista, opuesto tanto al primorriverismo como a las asociaciones católicas que habían asumido de forma oficiosa la representación de los estudiantes. No fue hasta 1928 cuando, a través del comité pro Unión Federal de 
Estudiantes Hispanos (UFEH), se creó una red a escala nacional, constituida por las FUE de los distintos distritos universitarios, y estas, a su vez, integradas por las Asociaciones Profesionales de Estudiantes (APE) que se constituían en cada instituto, facultad y escuela especial. En mayo de 1928, la UFEH protagonizó su primera gran huelga, en protesta por la suspensión dictada contra el catedrático Jiménez de Asúa por haber pronunciado una conferencia sobre el control de natalidad y contra el artículo 53 de la Ley de Reforma Universitaria. Los estudiantes impulsaron sucesivas oleadas de protesta con mayor difusión, radicalismo y continuidad, basadas en el modelo protestatario de la huelga patrocinada por un sindicato profesional que exigió el derecho a la representación y a la defensa de sus intereses por los cauces legales. La mayor profesionalización implicó también el ocaso del paternalismo profesoral y la exigencia de unas relaciones académicas más igualitarias.

El 24 de septiembre de 1929 fue derogado el polémico artículo 53, pero el enfrentamiento de los estudiantes con Primo ya había desbordado el cauce meramente académico. La agitación volvió a ganar las universidades en el segundo trimestre del curso 1929-30. Acosado desde todos los frentes, el dictador respondió disolviendo la FUE, que decidió ir a la huelga por no haber sido levantadas las sanciones a Sbert y a los profesores implicados en las protestas anteriores. El 22 de enero estalló un paro general universitario a escala nacional y con un neto carácter republicano, que fue apoyado por las principales fuerzas sindicales. Incapaz de resistir una ofensiva combinada de tal calibre, Primo abandonó el poder seis días después.

La caída de la Dictadura abrió el camino para una más activa presencia política de la UFEH, que fue politizando sus acciones en sentido antidinástico, hasta transformarse en uno de los actores clave del enfrentamiento con el régimen, a través de su protagonismo en acontecimientos como los «Sucesos de San Carlos» de los días 24 y 25 de marzo de 1931, cuando un asalto policial a la Facultad de Medicina en huelga causó dos muertos y i6 heridos ${ }^{6}$. La algarada estudiantil, de inequívoco tono revolucionario, fue muy bien aprovechada por la propaganda republicana, y precipitó la caída de la Monarquía menos de un mes después. La proclamación del nuevo régimen significó un triunfo particular para la FUE, y fue el momento culminante de su influencia política. Por Órdenes de 3 de junio y 28 de septiembre, la UFEH obtuvo la representación oficial de los estudiantes en los órganos de gobierno de las universidades. Su consagración como única representación escolar transformó a la entidad en una especie de agencia semioficial de gestión de actividades universitarias que contribuyó a aislarla de la masa de alumnos, sobre todo cuando sus dirigentes de los años de lucha antidictatorial finalizaron sus

6 Una narración pormenorizada de los sucesos de San Carlos, en el testimonio del director general de Seguridad Mola VIdal, Emilio: «El derrumbamiento de la Monarquía», en Obras Completas, Valladolid, Librería Santarén, 1940, pp. 763-815 y 88I-923. Otras versiones conservadoras, en Hoyos Y Vinent, José María de: Mi testimonio, Madrid, Afrodisio Aguado, 1963, pp. 71-100 y 210-216 y Jato Miranda, David: La rebelión de los estudiantes, Madrid, I975, pp. IO5-II2. La versión opuesta en VIDARTE, Juan-Simeón: No queríamos al rey. Testimonio de un socialista español, Barcelona, Grijalbo, 1977, pp. 367-370. 
estudios y se incorporaron a sus actividades políticas o profesionales. En abril de 1932, la FUE de Cataluña y Baleares abandonó la organización y se constituyó de forma autónoma como Federació Nacional d'Estudiants de Catalunya (FNEC) 7 . Además, la organización fue perdiendo afiliados a medida que la crisis económica limitaba las posibilidades de promoción a los jóvenes de clase media. La oficialización de la UFEH y la intromisión de los partidos en la vida académica provocaron una gradual deslegitimación de la acción sindical profesional.

Fue entonces cuando el movimiento estudiantil se comenzó a radicalizar y a politizarse, desplegando una estrategia competitiva eventualmente muy violenta. Desde 1932, la FUE perdió la iniciativa política en favor de los grupos antirrepublicanos, como las Juntas de Ofensiva Nacional Sindicalista (JONS) y, sobre todo, la belicosa Agrupación Escolar Tradicionalista (AET), que arrastraba a los afiliados de la apolítica Confederación de Estudiantes Católicos Españoles (CECE) en sus frecuentes enfrentamientos con los republicanos. El reflujo de los grupos de izquierda resultó evidente tras la victoria electoral derechista de noviembre de 1933, que coincidió con la fundación del Sindicato Español Universitario (sEU) afín a Falange Española. A partir de 1934, los estudiantes católicos fueron absorbidos progresivamente por JAP y Falange, mientras que la FUE lo fue por elementos más politizados de las juventudes comunistas y socialistas. La vorágine de violencia (que causó la muerte el 9 de febrero de 1934 del protomártir falangista Matías Montero) marcó el tránsito desde la tradicional agitación tumultuaria estudiantil hasta el pistolerismo, transformando la lucha ideológica universitaria en un problema de política nacional. La FUE vio clausurados sus locales, perdió el monopolio de la representación escolar y se desintegró a toda prisa tras la revolución de octubre.

La recomposición de la izquierda a partir de 1935 tuvo su reflejo en mundo estudiantil, cuando un Bloc Escolar Nacionalista de carácter antifascista lanzó el 8 de enero de 1936 un manifiesto en favor de la reposición del Patronato Universitario que había sido suspendido en Cataluña tras la revolución, y que fue respondido por la AET, la CECE y el SEU con una huelga que se hizo general los días 22 a 26. El paro animó la voluntad fusionista, en el ambiente de polarización previo a las elecciones de febrero. A imitación del proceso aliancista de izquierda consumado en abril de 1936 con la creación de la Juventud Socialista Unificada (JSU), el SEU, la AET, la CECE y las Juventudes Universitarias del partido alfonsino Renovación Española se embarcaron tras las elecciones en un proyecto de Frente Español Universitario que se vio truncado por la negativa de los católicos a diluirse en un organismo único8.

Durante la Guerra Civil, la fUE mantuvo su impronta radical, y apostó por la militarización del movimiento estudiantil, persiguiendo a los emboscados de

Figueras i SABATER, Arnau: Història de la FNEC. La Federació Nacional d'Estudiants de Catalunya de 1932 a 1986, Barcelona, Publicacions de l'Abadia de Montserrat, 2005.

«Hacia la sindicación única», Haz, I4, I4-2-1936, p. 6. El proyecto de sindicación única del $\mathrm{FEU}$, en Breve historia informativa del Sindicato Español Universitario, Madrid, Ediciones Haz, 194I, pp. $75-76$. 
retaguardia y apoyando de forma decisiva la integración de las ramas juveniles de los partidos republicanos en la Alianza Juvenil Antifascista (AJA) en agosto de 1937. Por su parte, el I2 de octubre de 1937 la AET, la CECE y otras agrupaciones estudiantiles de derecha fueron oficialmente integradas en el SEU, que se vio sometido a una rápida transición desde la agitación escuadrista a la oficialización como sindicato único y obligatorio en un modelo de Universidad de marcada impronta totalitaria, fijada según la Ley de Ordenación Universitaria de 25 de julio de $1943^{9}$. En ambos bandos, la juventud estudiantil organizada actuó como cantera para la oficialidad de los ejércitos, y desempeño además misiones asistenciales y de propaganda.

El ingreso en la Universidad, a partir de 1944-1945, de una minoría de hijos de la burguesía pertenecientes al bando perdedor, posibilitó la aparición en 1946-1947 de otra FUE, más profesional y liberal, que fue desarticulada por la policía entre marzo y abril de 1947. Con ello terminaba el periodo añorante de la República, y se iniciaba una nueva andadura del movimiento estudiantil, dirigido por una generación sin experiencia directa de la Guerra Civil ${ }^{\text {10}}$.

Entretanto, la Falange asumía el control de la Universidad, al tiempo que la sindicación obligatoria ponía al SEU en manos del Estado. Por Decreto de 23 de septiembre de 1939, el Consejo de Ministros confirmó oficialmente el monopolio seuista con la disolución del resto de las asociaciones de carácter estudiantil, como la AET y la CECE. En el iv Congreso Nacional Extraordinario del seu celebrado en El Escorial del 4 al 8 de enero de 1940 se produjo la fusión definitiva de carlistas, católicos y falangistas en un solo organismo. El sEu mantuvo el control político de los estudiantes mediante el fomento de un talante agresivo que trató de perpetuarse con el fomento de actitudes y valores de impronta castrense. La llamada «Quinta del SEU» que dominó las aulas en la década del cuarenta se caracterizó por su rechazo militante al espíritu de la Institución Libre de Enseñanza, su crítica radical a la República, su ensalzamiento del ideal de juventud, su orgullo excombatiente, su visión militar de la vida y su apuesta por el mantenimiento del estado de guerra en la Universidad a través de acciones coactivas y violentas.

En la década de los cincuenta se consumó la ruptura entre la juventud universitaria y el régimen, y nació un movimiento estudiantil democrático. Los inicios de la autonomía intelectual impulsada desde 1951 por el ministro de Educación Joaquín Ruiz-Giménez propiciaron un ambiente de liberalización que facilitó la actividad de los estudiantes más inquietos. El malestar escolar se hizo patente en noviembre 1955 tras la prohibición gubernativa de un Congreso Nacional Universitario de Escritores Jóvenes. En esa coyuntura, los estudiantes Javier Pradera, Enrique Múgica y Ramón Tamames decidieron convocar el 24 de enero de 1956

9 La caracterización del «SEU escuadrista», en Ruiz CARnicer, Miguel Ángel: El sindicato español universitario (SEU) I939-I965: La socialización política de la juventud universitaria en el franquismo, Madrid, Siglo xxI, I996, pp. 52-72.

1o Mesa, Roberto: Prólogo a Jaraneros y alborotadores. Documentos sobre los sucesos estudiantiles de febrero de 1956 en la Universidad Complutense de Madrid, Madrid, Universidad Complutense, 1982, p. I3. 
un Congreso Nacional de Estudiantes que propusiera la democratización de las organizaciones escolares. Ante la amenaza de celebración de elecciones libres, el caserón de San Bernardo fue asaltado el día 7 de febrero por la Guardia de Franco. Como en épocas pasadas, un ataque protagonizado por actores ajenos a la normal actividad académica fue sentido por los estudiantes como una agresión. Los sucesos de febrero del 56 revelaron dos desencuentros básicos: el del cuerpo estudiantil con respecto al franquismo, pero también la creciente disfuncionalidad entre el carácter conservador del régimen y la retórica de «revolución pendiente» que seguían alimentando las juventudes del SEU ${ }^{\text {II }}$.

Desde entonces, la dirección del SEu fue abandonando la demagogia falangista en favor de una pretendida eficacia y profesionalidad, que consideraba más cercanas a las inquietudes estudiantiles del momento. La tímida ampliación de la representatividad y el auge que cobraron las Cámaras de Facultad permitió la aparición de líderes estudiantiles que llevaron la lucha al seno del sindicato oficial. Las movilizaciones de 1956-1957, la tímida apertura del SEU en I957-I958 y la desarticulación del aparato del PCE en la Universidad de Madrid facilitaron la aparición de nuevas organizaciones clandestinas, como la Agrupación Socialista Universitaria (ASU), creada en Madrid en febrero de 1956, y la Nueva Izquierda Universitaria (NIU), cuyo origen estuvo en el Frente de Liberación Popular (FLP), plataforma de convergencia cristiano-marxista creada entre fines de 1957 y la primavera de I958. También en 1957 se creó la Unión Democrática de Estudiantes (UDE) como punto de unión de las fuerzas democráticas vinculadas a la Universidad. Las organizaciones clandestinas orientaron su actuación a los ámbitos sindical y profesional, para sacar el máximo provecho de las nuevas plataformas legales de representación electiva. El Decreto de i8 de septiembre de i96I sobre organización del SEU trató de frenar la representatividad de la oposición en los Consejos de Cursos y Cámaras Sindicales, dotando a la autoridad académica de un mayor poder de supervisión y coacción. Consecuencia de esta regresión fue el aumento de la lucha estudiantil contra el sindicato y el régimen en su conjunto. En el otoño de 1963 se creó la Federación Universitaria Democrática Española (FUDE) con el objeto de «agrupar a todos los universitarios disconformes con el sindicato obligatorio» en una organización autónoma estudiantil de carácter democrático.

A partir de 1965 , los estudiantes diversificaron su estrategia e intereses. El I7 de enero, varias facultades se negaron a participar en el nombramiento del jefe de

" Sobre los sucesos del 56, véanse León, Sergio (seud. de Roberto Mesa): «Notas sobre el movimiento estudiantil en España», en Horizonte Español, Cuadernos de Ruedo Ibérico, vol. II, París, 1972, pp. 157-177; Lizcano, Pablo: La generación del 56. La Universidad contra Franco, Barcelona, Grijalbo, 1981, pp. 132-I53; AbeLLÁn, José Luis: «La rebelión estudiantil del 56», en Historia del franquismo, Madrid, Diario 16, 1985, vol. I, pp. 386-394; Álvarez Cobelas, José: Envenenados de cuerpo y alma. La oposición universitaria al franquismo en Madrid (1939-1970), Madrid, Siglo XXI, 2004, pp. 72-79, y Hernández Sandoica, Elena; Baldó Lacomba, Marc y Ruiz Carnicer, Miguel Ángel: Estudiantes contra Franco (1939-1975). Oposición política y movilización juvenil, Madrid, La Esfera de los Libros, 2007, pp. II8-I36. 
distrito de la Universidad de Madrid y exigieron la desaparición del seu. El 24 de febrero, unos 5.000 reclamaron la implantación de un sindicato libre, autónomo y representativo, la amnistía total para los catedráticos y estudiantes expedientados y la libertad de expresión docente y discente. Al encaminarse con Aranguren, García Calvo y otros profesores hacia el pabellón de gobierno de la Universidad, la comitiva fue dispersada por la policía. En pocos días, 84 centros universitarios se separaron del SEU, entre ellos casi todos los de Barcelona y Madrid. Se constituyeron juntas de delegados, se institucionalizó el movimiento asambleísta y se situó como objetivo inmediato el sindicato libre ${ }^{12}$. El 7 de abril, el Gobierno publicó un Decreto que hizo desaparecer de hecho al sindicato falangista, que fue dividido por ramas en Asociaciones Profesionales de Estudiantes (APE). La transformación del otrora potente entramado escolar falangista en una anodina Delegación-Comisaría para meros asuntos de servicios supuso su liquidación como organismo de encuadramiento y representación de los estudiantes.

\section{Ecos del 68 en España: la cúspide de la movilización contra la dictadura franquista}

La recuperación de la movilización escolar en España a fines de los sesenta, tras la crisis de 1956 que acabó con la hegemonía del seu y la agitación lanzada por los sindicatos democráticos de estudiantes universitarios (SDEUs) en 1964-I965, debió mucho a los nuevos repertorios de protesta que se fueron ensayando en las universidades norteamericanas y europeas a partir de 1964. Esta etapa de movilizaciones se caracterizó por una estrategia de protesta más flexible e informal, de carácter frecuentemente lúdico y performativo (manifestaciones, sentadas, asambleas libres, con alta participación estudiantil, debido en parte a la fuerte masificación de algunas facultades), pero con una voluntad claramente reivindicativa, canalizada por organizaciones estables, como el Sindicato Democrático de Estudiantes del Distrito de Barcelona-SDEUB-impulsado tras la accidentada reunión semiclandestina de la Caputxinada de 9 de marzo de $1966^{13}$ o el sDEUm creado en Madrid el 7 de diciembre de ese año. Estos sindicatos articularon las demandas profesionales que encubrían reivindicaciones políticas, y realizaron una importante labor de coordinación a nivel estatal (Reuniones Nacionales Coordinadoras) en el favorable contexto internacional de mayo de 1968. Las asambleas libres fueron un útil instrumento de formación de la identidad colectiva y un foro de discusión que alimentó el movimiento escolar. Los SDEU, con base en las Cámaras de Facultad, actuaron como mediadores entre los partidos políticos de oposición activos en los campus y la práctica asambleísta de los centros docentes. Si hasta 1965 la movilización se había dirigido a luchar contra el SEU y reivindicar un

I2 Palazuelos, Enrique: Movimiento estudiantil y democratización de la Universidad, Madrid, Manifiesto, I978, p. 3I.

${ }_{13}$ Colomer i Calsina, Josep María: Els estudiants de Barcelona sota el franquisme, Barcelona, Curial, 1978, vol. I, pp. 215-240. 
sindicalismo libre, autónomo y representativo, desde fines de los sesenta ya se dirigía directamente contra el régimen a través de los partidos políticos.

El movimiento estudiantil desplegó un repertorio disruptivo extraordinariamente innovador, constituido de huelgas, establecimiento de universidades paralelas y populares, intervenciones obstruccionistas en edificios académicos o gubernamentales (go-in, y ocupaciones «blancas» con interrupción de clases y otras actividades perturbadoras del normal orden académico) y en la calle (sit-in, shit-in, chant-in, picketing-line), marchas, bailes de la serpiente copiados de los estudiantes japoneses, manifestaciones tumultuarias relámpago o permanentes, happenings (escenificaciones festivas), pintadas y otro tipo de enfrentamientos en donde la provocación contraviolenta y la distorsión (burlas, parodias teatrales) aparecían como la respuesta a la violencia «estructural» de un adversario cada vez más radicalizado, todo lo cual ponía en evidencia la violencia policial y desacralizaba el estatus y las funciones de la autoridad, con el objeto de movilizar a los estudiantes y a la sociedad en su conjunto.

Durante los años finales de la década, el movimiento estudiantil, espoleado por las circunstancias de orden doméstico (declive del asociacionismo oficial) e internacional (agitación universitaria), alcanzó la cúspide de la movilización, que parecía contagiar al conjunto de la sociedad. Las innovaciones tácticas del movimiento estudiantil condujeron a choques cada vez más violentos con otros grupos rivales y con las instituciones represivas oficiales, lo que limitó sus capacidades de acción y desencadenó la inevitable oleada de desánimo. Cuando la participación decayó y la perspectiva utópica del 68 se fue alejando, comenzaron a predominar formas de protesta más convencionales, vinculadas de forma creciente a las estrategias unitaristas de las plataformas políticas de oposición, mientras que las actitudes más radicales tendieron al aislamiento, la defección, la involución sectaria y la violencia, sufriendo una represión oficial cada vez más intensa y localizada.

Cuando la experiencia de los sindicatos democráticos alcanzaba su máxima generalización, comenzaron a hundirse primero en Barcelona y luego en Madrid. En la ciudad condal, la radicalización estudiantil posterior a mayo del 68 fue una reacción frente al acoso oficial en contra del SDEUB, pero también una expresión local de los nuevos movimientos de protesta y de las nuevas vías de representación y de acción que se estaban ensayando ${ }^{\mathrm{I4}}$. Barcelona fue la primera Universidad que experimentó con la «democracia asamblearia» y la autogestión, creando plataformas conjuntas de acción a inicios del curso I968-1969, combinando el repertorio convencional de protesta (huelgas, manifestaciones...) con las nuevas «modas» importadas de París (ocupaciones de cátedras, sentadas...), que implicaban un enfrentamiento directo contra los catedráticos y las autoridades. La combinación de estrategias «legales» más o menos toleradas con estrategias ilegales de protesta política se articuló en varios niveles: las plataformas legales (Delegaciones de Estudiantes, Cámaras de Facultad), las organizaciones semilegales de masas (FUDE o SDEU) y las organizaciones de vanguardia ilegales (partidos políticos

$14 \quad$ Ibidem, p. 394. 
clandestinos), con el objeto de diversificar los actores y las oportunidades de acción y de protesta ${ }^{15}$. Pero en el momento del declive de la movilización y de la represión se produjo una disminución drástica de la participación y un deterioro del valor de las formas de lucha del movimiento escolar, que quedaron reducidas a las movilizaciones callejeras de carácter antirrepresivo (contra la actitud provocativa de la Policía que tomaba por asalto los recintos universitarios), a la convocatoria de huelgas indefinidas (como el paro general que tuvo lugar el 26 de febrero de 1974) y a la celebración puntual de jornadas de lucha (como la manifestación de estudiantes en el primer aniversario del «caso Ruano» el i9 de enero de 1970) y de protesta, como la huelga a escala nacional convocada en contra de la Ley General de Educación (LGE) el i4 de febrero de $1972^{16}$ o la desarrollada el 9 de mayo de 1974 contra la Ley de Selectividad. Otro instrumento de movilización era la huelga activa, acompañada de estudio en comisiones de los proyectos oficiales, debates, actividades culturales y boicot a las clases. Pero todas estas modalidades reivindicativas tenían muy escaso eco, salvo en momentos concretos, fuera de los campus, y apenas tenían capacidad para ofrecer alternativa trasformadora alguna para los problemas que generaba el nuevo modelo de Universidad masificada.

Un Decreto de 20 de septiembre de 1968 suspendió las moribundas APE y aprobó nuevas formas de asociación estudiantil, bajo el control de las autoridades académicas. El ascenso de las luchas obreras y de las movilizaciones políticas unitarias aceleró la decadencia de los grupos políticos de base exclusivamente universitaria. La radicalización y las actitudes clandestinas campantes entre los escolares entre I968 y 1973 facilitaron la aparición de grupos ultrarrevolucionarios que se alejaron de las referencias en los movimientos de masas, y consideraron que el sistema de delegados electos no era plenamente representativo, sino que el órgano soberano del movimiento estudiantil debía ser la asamblea. Como de costumbre, Madrid y Barcelona llevaron la voz cantante de la protesta. La elección pautada de representantes de los estudiantes y la gestión sindical dirigida al diálogo con las autoridades académicas pactadas por el sDEUB fueron sustituidas progresivamente por la actuación caótica de los comités de acción y los comités de curso clandestinos, y por la democracia directa emanada de unas asambleas de Facultad que a menudo tomaban sus decisiones por aclamación ${ }^{17}$. Se puede decir que el modelo de sindicato democrático saltó por los aires por el exceso de asamblearismo ${ }^{18}$. En octubre de

15 Rodríguez Tejada, Sergio Ignacio: «La caída de la organización universitaria del PCE en Valencia en manos de la política franquista (197I): un ejemplo de la represión contra el movimiento estudiantil», en Comunicaciones presentadas al II Encuentro de Investigadores del Franquismo: Alicante, II, I2 y I3 de mayo de 1995, Alicante, Inst. de Cultura Juan Gil-Albert, Univ. de Alicante, Univ. de Valencia, FEIs, vol. 2, I995, p. 90.

${ }_{16}$ La lucha contra la Ley General de Educación en el curso 1971-1972 y las fuertes medidas represivas adoptadas por el Ministerio de Educación, con la implantación de consejos de disciplina académica, en Pérez, Alejandro: «La reconstrucción fallida: el movimiento estudiantil de r97I a 1976», Materiales. Crítica de la Cultura, 2 (1977), pp. 93-102.

${ }_{17}$ Colomer i Calsina, Josep María: op. cit., pp. 394-395.

I8 Sanz Díaz, Benito: La oposició universitària al franquisme, València, 1939-1975, Valencia, Servei d’Informació a l'Estudiant-Dise, Universidad de Valencia, [¿̇1999?], pp. 76-77. 
I968, el SDEub había dejado prácticamente de existir, mientras que se multiplicaba la aparición de grupos políticos radicales bajo la influencia de los acontecimientos del mayo francés. Todos estos grupos presentes en la Universidad de Barcelona entraron en crisis a partir de 1969, disolviéndose o fragmentándose, aunque el retroceso se frenó transitoriamente en 1973 , cuando se generalizó la demanda de una ruptura democrática.

En Madrid, los intentos de revitalizar el sDeum resultaron baldíos, ya que sus representantes no fueron secundados en todas las facultades, e incluso algunos cursos de Filosofía y Letras votaron en su contra. A pesar de que el 3 de mayo de 1967 el sindicato decía contar con 27.000 afiliados, en el curso siguiente entró en crisis terminal por culpa de la represión policial; por la falta de politización de las elecciones; por la ausencia de continuidad en la actividad sindical de la mayor parte de los estudiantes; por las luchas espontáneas que se fueron desatando desde los niveles de curso, y por la progresiva defección de grupos más activos y radicales como el FLP, PCE-i y PCE $(m-1)^{19}$. Mientras que el comunismo oficial apostaba por la continuidad del SDEUM como correa de trasmisión de la cooperación con el movimiento obrero bajo supervisión del partido, los grupos marxista-leninistas preconizaban el trabajo en las asociaciones intermitentes (plataformas) a través de la actividad de vanguardia. El sindicato quedó definitivamente desarticulado con motivo del estado de excepción declarado de enero a marzo de 1969. Los grupos izquierdistas que habían participado coaligados en las elecciones de noviembre de 1967 y se habían hecho con el control de los SDEU en las universidades más importantes, empezaron a pronunciarse contra los mismos cuando la represión arreció, y en marzo de 1968 comenzaron a abandonarlos ${ }^{20}$.

Desde 1968 el movimiento escolar fue abandonando el debate sobre el modelo de Universidad y de educación, y se centró en la cuestión de la toma del poder. De este modo hizo su aparición la Nueva Izquierda, movimiento de inconformismo político e intelectual que al plantear el debate de la superación de la fase de reivindicación escolar por la adopción de posturas francamente revolucionarias radicalizó el movimiento estudiantil y lo enfrentó con el PCE, que seguía defendiendo el proyecto unitario de los SDEU, cuya actividad prosiguió, aunque muy mermada, hasta después del estado de excepción de 1969. Fue la era dorada del activismo, que anteponía los problemas tácticos a los estratégicos e incluso los $\operatorname{organizativos}^{21}$. La aparición de grupúsculos activistas de extrema izquierda impidió la consolidación del movimiento estudiantil posterior al 68, y este déficit de institucionalización dio prioridad a fórmulas organizativas informales como las asambleas (órgano máximo de representación estudiantil) y los comités abiertos,

19 Formentor, Davira (seud. de Pablo Lizcano y Mamen Gutiérrez): «Universidad: crónica de siete años de lucha», en Horizonte Español 1972, París, Ruedo Ibérico, 1972, vol. II, p. 207.

${ }^{\circ}$ Valdevira González, Gregorio: La oposición estudiantil al franquismo, Madrid, Síntesis, 2006, p. I09.

${ }_{21}$ Nieto, Alejandro: La ideología revolucionaria de los estudiantes europeos, Barcelona, Ariel, 1972, p. 228. 
más cercanos al principio de autogestión que al centralismo democrático o el parlamentarismo democrático ${ }^{22}$.

La presencia de actores, estrategias y objetivos tan abigarrados derivó en una radicalización de la protesta cuyo corolario de conflicto y violencia acabó por desmotivar a la mayor parte de la masa estudiantil. El asalto de medio centenar de personas al Rectorado de la Universidad Central de Barcelona el i7 de enero de 1969 conllevó el cierre del recinto académico y la declaración del estado de excepción en todo el país a partir del día 24, tras la muerte del estudiante de Derecho Enrique Ruano Casanova, miembro del FLP, que fue asesinado de un disparo el is de enero por policías de la Brigada Político-Social, y después arrojado por la ventana de un séptimo piso para simular un suicidio ${ }^{23}$. El estudiante madrileño Ignacio Larrazola también murió en las manifestaciones de protesta convocadas tras este asesinato. La Policía ocupó las facultades de Madrid. Se prohibieron reuniones, cámaras, asambleas, actividades culturales y la colocación de carteles informativos, mientras que los miembros más conspicuos del SDEUM fueron sistemáticamente detenidos ${ }^{24}$. La suspensión de derechos se mantuvo hasta el 2I de marzo, y durante las dos primeras semanas de vigencia del estado de excepción se detuvo a más de trescientas personas, en su mayoría escolares, y a su conclusión se había encarcelado a 735 personas, 315 de ellas estudiantes ${ }^{25}$. La represión franquista ya no fue solo académica (con el corolario habitual de expedientes, inhabilitaciones, cierre de las universidades y dispersión de los centros) o informativa (con el restablecimiento de la censura de prensa en febrero-abril), sino también policial y gubernativa, basada en registros nocturnos y detenciones (como las de Fernando Savater, José María Mohedano y Alfonso Carlos Comín, entre otros), destierros (de los profesores Paulino Garagorri, Raúl Morodo, Pedro Schwartz, Javier Muguerza, Francisco Bustelo y Roberto Mesa en Políticas y Económicas, y Elías Díaz, Gregorio Peces-Barba, Óscar Alzaga y Manuel Jiménez de Parga de Derecho) ${ }^{26}$, malos tratos en comisaría,

22 Déniz Ramírez, Francisco Antonio: La protesta estudiantil: estudio sociológico e histórico de su evolución en Canarias, Madrid, Talasa Ediciones, 1999, p. 3I.

${ }_{23}$ Los sucesos de Barcelona en «El día que asaltaron el rectorado de Barcelona», Gaceta Universitaria, n. $^{\circ}$ I34-I35, $2 .^{a}$ quincena enero 1970, p. 5. La muerte de Ruano en Domínguez Rama, Ana: "Cinco días de manipulación informativa: la noticia de la muerte de Enrique Ruano en la prensa franquista», en Bueno, Manuel; Hinojosa, José y García, Carmen (coords.): Actas del I Congreso sobre la Historia del PCE, I920-1977. Oviedo, 6, 7 y 8 de mayo de 2004, Madrid, Fundación de Investigaciones Marxistas, 2007; García AlCALÁ, Julio Antonio: Historia del «Felipe» (FLP, FOC y ESBA): de Julio Cerón a la Liga Comunista Revolucionaria, Madrid, CePc, 200I, pp. 245-250; SANz Díaz, Benito: op. cit., p. 87 y Valdevira GonZÁlez, Gregorio: op. cit., 2006, pp. I43-I49.

24 Formentor, Davira: op. cit., p. 206.

${ }_{25}$ Aguilar Cestero, Raúl: «El despliegue de la Universidad Autónoma de Barcelona entre I968 y 1973: de fundación franquista a motor del cambio democrático en Cataluña», Cuadernos del Instituto Antonio de Nebrija de Estudios sobre la Universidad, io (2007), p. I51. Sobre el estado de excepción declarado el 24-I-I969 y su justificación oficial, véase Ysàs, Pere: Disidencias y subversión. La lucha del régimen franquista por su supervivencia, 1960-1975, Barcelona, Crítica, 2004, pp. 29-34.

${ }^{26}$ «La Junta de Estudiantes denuncia la represión. SDEUM, Madrid mayo 1969», en AH.PCE, Publicaciones de la Universidad, vol. 20/I. 
multas a instancia de la Brigada Político-Social, negativa a la expedición de certificados de buena conducta, pasaportes y carnets de conducir, prohibición arbitraria de realizar milicias universitarias y apertura de juicios en el Tribunal de Orden Público (TOP) y en los tribunales militares en aplicación del Decreto de 2 de septiembre de 1960 sobre Bandidaje y Terrorismo, que consideraba rebelión militar la divulgación de noticias falsas o tendenciosas, las reuniones de la oposición o las huelgas políticas. Con todo, siempre hubo malos entendidos entre los dirigentes del movimiento estudiantil -muchos de ellos vástagos de una parte de la élite social española de la época- y de las organizaciones obreras, más expuestos a la represión institucional y que despreciaban a los primeros como «izquierdistas de salón».

Los centros universitarios clausurados con motivo de la proclamación del estado de excepción fueron abriendo escalonadamente sus puertas hasta la Semana Santa. A partir del curso 1969-1970, la Facultad de Ciencias Políticas y Económicas operó como centro líder del movimiento estudiantil en la Complutense y en todo el distrito universitario de Madrid. Las protestas se plantean en torno a la reforma de los planes de estudio, la autoorganización (que se redujo a partir de la constitución del SDEUM en I966-1967), la lucha contra la represión policial y académica y contra la dictadura ${ }^{27}$. Tras un «otoño caliente» que marcó el devenir universitario en los comienzos del año académico, el 20 de enero de 1970 dos millares de estudiantes se manifestaron junto al Arco de la Victoria de Madrid en el primer aniversario de la muerte en Enrique Ruano ${ }^{28}$. Durante el curso I970I97I continuó la lucha desincronizada en cada distrito. Tras la desaparición de los SDEU a fines de los sesenta solo quedaban incólumes las Juntas de Facultad, pero entonces aparecieron las coordinadoras de comités de curso, como alternativa a la desarticulación de los SDEU por la Policía. Los comités se extendieron a otros distritos en noviembre de 1971, pero el PCE los abandonó durante el año 1973-1974, y ese verano también los dejaron de lado otros grupos activistas como la Joven Guardia Roja y Bandera Roja. Los comités de curso languidecieron durante el curso siguiente, y en el curso 1975-1976 se pudo certificar su defunción ${ }^{29}$.

$\mathrm{La}$ actividad estrictamente escolar, ahora más hostil que antaño hacia profesores y catedráticos, quedó truncada con ese estado de excepción permanente, del que surgirían los grupos «gauchistas» clandestinos que se enfrentaron a los SDEU, cuyas estructuras se fueron vaciando de contenido desde el curso 1968-1969 en favor de una dinámica partidista que condujo incluso al enfrentamiento físico entre activistas ${ }^{3 \circ}$.

27 Camarero González, Arturo: «La expansión del movimiento estudiantil en Madrid: formas de movilización y organización. Solidaridad con los estudiantes», Revista Internacional de Sociología, 43 (julio-septiembre 1982), p. 437.

${ }_{28}$ «El movimiento estudiantil en el Curso 69-70», Vanguardia. Organización Universitaria de Madrid del PCE, I9-X-1970, documentación cortesía de Elena Sánchez Durán.

29 Hernández Sandoica, Elena; Ruiz Carnicer, Miguel Ángel y Baldó Lacomba, Marc: op. cit., p. 358 .

30 Rodríguez TeJada, Sergio Ignacio: «Estratègies d'oposició i moviment estudiantil antifranquista: una reflexió des del cas valencià», Recerques, 44 (2002), pp. I69-170. 
Los sindicatos democráticos fueron desapareciendo en medio de la oleada de fervor revolucionario y de la intensa represión desatada por el régimen en forma de militarización de la Universidad para conjurar unas posibles «jornadas de mayo». Pero en realidad, como hemos visto, la decadencia sindical ya había comenzado en 1967 en Barcelona y en 1968 en Madrid, por circunstancias de orden interior antes que por influencias foráneas. Los procesos electorales comenzaron a declinar por el rechazo y el abstencionismo de los estudiantes, hasta el punto de que en 197I los rectores y decanos dejaron de convocar elecciones. A partir de ese año, la implantación de una ambiciosa reforma educativa, gestionada de forma autoritaria, y que imponía la descentralización de tareas gestoras antes que una auténtica autonomía universitaria al otorgar un poder omnímodo a los rectores como representantes del Ministerio de Educación y Ciencia, empujó al movimiento estudiantil a iniciar una campaña de denuncia del contenido clasista de LGE, que pretendía el «desvío» de parte del alumnado hacia la Formación Profesional y la desmasificación de las universidades mediante la aplicación de estrictos criterios selectivos ${ }^{31}$. Los SDEU desaparecieron, y la protesta, dentro del marco impuesto por la LGE, pasó entre I97I y 1974 en buena medida a manos de los estudiantes de Bachillerato, los maestros y los profesores no numerarios (PNNs), que en 1975 constituían casi el $80 \%$ del profesorado universitario ${ }^{32}$.

El curso 197I-1972 se vivió en las aulas en un ambiente de «lucha final», con la intención de arrastrar a amplios sectores sociales, y en concreto a la oposición democrática, a una ofensiva política que abriese la posibilidad de liquidación revolucionaria del régimen franquista. Fue el momento de mayor auge del espontaneísmo y el antiautoritarismo, y de idealización de «la lucha» como expresión de la incertidumbre política y el malestar cultural. A inicios de los setenta los repertorios de acción adoptaron un carácter más rupturista y violento: junto con el tradicional lanzamiento de octavillas, las pintadas llamando al control y al poder estudiantiles y los mítines espontáneos en el metro, aparecieron comandos en las facultades, que se enfrentaban con la Policía con cócteles Molotov, pedradas y barricadas, provocando el desalojo masivo de las facultades ${ }^{33}$. La intensidad y fisonomía de la protesta contra la LGE variaba de una facultad a otra y dependía del grado de experiencia y de coordinación existente en cada recinto universitario: las continuas asambleas, más deliberativas que decisorias, restaban fuerza a las resoluciones que se tomaban en las mismas.

Tras la crisis de los SDEU se convocó una I Reunión General de Universidades (RGU) el 30 de enero de 1972, que decidió convocar una huelga nacional para el I4 de ese mes en contra de la LGE, y una nueva jornada de lucha para el 6 de marzo.

${ }^{31} \quad$ El intento de reorientación de la política de enseñanza a través de la LGE, que impuso una cierta racionalización tecnocrática y una moderada democratización, y estuvo en vigor durante 35 años, en Aguilar Cestero, Raúl: op. cit., pp. 32-35, y Valdevira González, Gregorio: El movimiento estudiantil en la crisis del franquismo: la Universidad Complutense (1973-1976), Madrid, Universidad Complutense, 200I, pp. 490-493.

32 Palazuelos, Enrique: op. cit., pp. 5I-56.

33 Aguilar Cestero, Raúl: op. cit., p. 156. 
Una segunda convocatoria interuniversitaria, que se celebró en Montserrat el 28 de febrero, no logró mantener el Comité Nacional de Huelga como órgano coordinador del movimiento. La III RGU tuvo lugar en Madrid el 8 de abril de 1972, y convocó una huelga general para el in de ese mes. Pero la estrategia unitaria apenas pasó del simple proyecto. Las RGU vieron truncada su continuidad hasta su revitalización en la IV RGU celebrada del I2 al I4 de abril de I974, que propuso la declaración de una nueva huelga general para el 8 de mayo ${ }^{34}$. Otra Reunión General que tuvo lugar el 20 de febrero de 1975 finalizó con la creación de una Permanente sin poder decisorio. La última RGU, que tuvo lugar el 29 de abril de 1975 , convocó una jornada de lucha para el día siguiente a favor de la apertura de la Universidad de Valladolid.

En el curso 197I-1972 se intensificó la lucha contra la LGE y los numerus clausus. Entre el i6 de diciembre de i971 y el Io de enero de 1972 se cerraron las Facultades de Derecho, Filosofía y Letras y Ciencias Políticas de Madrid. La Facultad de Medicina inició una huelga de ocho meses por la reforma de los planes de estudio que degeneró en pedradas a la Policía, vuelco de coches, un encierro en el Hospital Clínico y la pérdida de matrícula para 4.00o estudiantes el I3 de enero, lo que cuatro días más tarde arrastró a un paro general de la UCM y la UAM que se extendió a la Politécnica el día i8. La agitación ganó a todas las facultades de Medicina del país, con huelgas, manifestaciones y ocupación de cátedras en Valladolid, La Laguna, Málaga y Zaragoza. La Coordinadora Amplia de las tres universidades de Madrid convocó una nueva huelga general para el I de marzo.

Las continuas movilizaciones que tuvieron lugar durante el curso 197I-1972 en las principales universidades del país, y en especial en la Complutense, polarizaron el conjunto del movimiento estudiantil contra la LGE y alcanzaron un amplio eco social. Todo ello llevó a que, incluso antes de la sustitución de Villar Palasí por Julio Rodríguez Martínez en junio de 1973, el MEC protagonizase un giro claramente contrarreformista en la política universitaria, que el 26 de julio de 1972 dio lugar a la aplicación por decreto en las Universidades Complutense y Autónoma de Madrid del artículo 67 de la LGE que preveía la supresión por un año de sus Estatutos provisionales, lo que detuvo en seco la autonomía en la gestión y la representatividad de los rectores. En las jornadas de lucha, la Policía tomaba desde la primera hora de la mañana las facultades, retiraba carteles, impedía asambleas, detenía a estudiantes, desalojaba centros y controlaba el campus con fuerzas de a pie y a caballo y con helicópteros. La vigilancia se extendía a los barrios colindantes y a los lugares de concentración y manifestación habituales ${ }^{35}$.

La decadencia del movimiento estudiantil antifranquista, que culminaría su descomposición en junio de 1976, se inició en el curso 1972-1973, en vista de la dura represión gubernativa y académica y de los efectos de la política selectiva prevista en la LGE. La aplicación en universidades como la de Barcelona de los

34 La lucha contra la LGE y represión desde el curso 1971-I972 con la imposición de los nuevos planes de estudio en Valdevira GonZÁlez, Gregorio: op. cit., 2006, pp. 154-156.

35 Valdevira González, Gregorio: op. cit., 200I, pp. 786-787. 
decretos represivos de julio de 1972, la política de cierres y la penuria de dotaciones ante el incremento imparable del número de alumnos produjeron una degradación de los estudios que se manifestó en el abandono masivo de los estudios por parte de numerosos alumnos de facultades como Filosofía y Económicas ${ }^{36}$. La crisis de la universidad tradicional y la erosión de la vida universitaria, que no atajaron los gobiernos tardofranquistas, condujeron a un fuerte absentismo, sobre todo en los centros no experimentales, y debilitó e hizo decaer al movimiento estudiantil a partir de 1972. A pesar de la creciente represión académica y policial (con ocupación de los campus entre 1969 y 1973) y de la desunión y disolución del movimiento estudiantil a partir de 1972 en las más amplias movilizaciones populares del tardofranquismo, es preciso reconocer que los estudiantes fueron el único colectivo de oposición que logró crear una organización democrática de masas y acabar progresivamente con una institución política creada por el régimen: el SEU.

Se acercaba la hora de la política de partidos, sobre todo cuando las dificultades para mantener la movilización escolar pasaban la factura del desánimo y la defección entre los escolares ${ }^{37}$. Los sectores más moderados se fueron retrayendo de la lucha: en el tramo final de los sesenta, solo un $20-25 \%$ de estudiantes eran políticamente activos; la mitad se movilizaba o no en función de la radicalidad del enfrentamiento exigible, y el $25 \%$ restante se oponía, aunque solo una minoría de extrema derecha vinculada al Opus Dei no manifestaba esta oposición activamente, sino que se limitaba a desaparecer de la escena cuando se planteaban situaciones de conflicto. En 1969 existía una minoría muy politizada que, de manera más o menos consciente, se pronunciaba por alternativas de corte socialista ${ }^{38}$. En todo caso, se percibía un fuerte compromiso democrático, pero también una desafección corporativa creciente marcada por el funcionamiento caótico de la Universidad ${ }^{3}$. Fuera de las aulas, las opiniones políticas eran aún más pesimistas: en 1968 , el $69 \%$ de los estudiantes encuestados opinaba que la juventud no tenía ninguna influencia en el quehacer político del país. Un $40 \%$ prefería la democracia (un $23 \%$ la consideraba el régimen más deseable para España), y se mantenía la mayor empatía por las formas de gobierno republicano ${ }^{40}$.

En el primer gobierno de la Monarquía, el ministro Carlos Robles Piquer trató de canalizar la participación mediante una reforma en profundidad del

36 Análisis del curso 1972-73 elaborado por el Comité Universitario del Psuc en la Universidad de Barcelona (1973), en AH.PCE, Nacionalidades y regiones, Cataluña (PsUC), jackets 2.483-2.486. Según esta fuente, el control del movimiento estudiantil barcelonés lo tenían BR, el PCE-i y el PCE.

${ }_{37}$ Nicolás Marín, Encarna y Alted Vigil, Alicia: Disidencias en el franquismo (1939-1975), Murcia, Diego Marín Librero-Editor, 1999, p. 74.

${ }_{38}$ «El movimiento universitario ante el nuevo curso 1968-69. Documento elaborado por el conjunto de responsables de las organizaciones de estudiantes comunistas, con la dirección del Partido» (1969), p. 3, en AH.PCE, Fuerzas de la Cultura, caja I23.

39 Torregrosa, José Ramón: La juventud española. Conciencia generacional y política, Esplugues de Llobregat, Ariel, 1972.

40 Durán Heras, María de los Ángeles et al.: Los universitarios opinan, Madrid, Ed. Almena, 1970, p. 95. 
EDUARDO GONZÁLEZ CALLEJA

Decreto de Participación Estudiantil de 17 de octubre de 1974, que permitió ampliar el alcance de las libertades de reunión y expresión, al tiempo que se daban pasos en la dirección de una mayor autonomía universitaria. Los intentos de aplicar los postulados más liberalizadores de la LGE a través del Decreto sobre Participación Estudiantil llevaron a su apogeo a las movilizaciones de protesta, cuyo auge se manifestó en el incremento de la circulación de la prensa ilegal de partido, la proliferación de la propaganda clandestina, las jornadas de lucha por la amnistía, las asambleas, los actos culturales, las manifestaciones (sobre todo entre enero y marzo de 1975), los encierros, los desalojos, las manifestaciones y los cierres más o menos forzados de los recintos universitarios, que tuvieron carácter indefinido en Salamanca, Deusto y Oviedo, y temporal en Sevilla ${ }^{4}$. La oposición estudiantil siguió atacando la LGE, pero debido a su falta de coherencia política y a la constante represión de que fue objeto no logró arrastrar al movimiento obrero y a la oposición antifranquista en su conjunto hacia la ruptura política. Más bien fueron los partidos políticos, las organizaciones obreras y los movimientos sociales más radicalizados los que movilizan a los estudiantes en apoyo y solidaridad con la lucha obrera, tanto en la Universidad, como en los centros de enseñanza secundaria para aquellas zonas geográficas que no poseen en esos años campus universitarios públicos. Además, la propuesta ministerial de participación escolar agudizó la división entre los distintos grupos políticos presentes en la Universidad: el PCE, la Joven Guardia Roja y Bandera Roja optaron por la participación, y trataron de aprovechar esta nueva reglamentación sobre participación estudiantil para lograr la tan ansiada coordinación estatal a favor de una universidad abierta y democrática. Por el contrario, el Frente Socialista Universitario (sección estudiantil de las Juventudes Socialistas desde inicios de los setenta), la Organización Revolucionaria de los Trabajadores (ORT), el Movimiento Comunista de España (MCE), la Liga Comunista Revolucionaria (LCR) y la FUDE-FRAP (que actuaba como sección universitaria del PCE[m-l]) rechazaron entrar en el juego de la contemporización y preconizaron la huelga general y el boicot absoluto a las elecciones, que se celebraron en noviembre de 1974 en un marcado ambiente abstencionista en universidades como la Complutense de Madrid, la Central de Barcelona, Salamanca, Valencia, Bilbao, Zaragoza, Santiago y Valladolid, donde la detención el i8 de enero de 1974 y la «caída» desde una ventana de la comisaría del representante estudiantil José Luis Cancho (miembro de la Joven Guardia Roja), que quedó inválido, había desatado dos días más tarde un paro académico de 48 horas, tras del cual se decretó el cierre de la Universidad hasta el 29 de enero. El 8 de febrero, las autoridades académicas decidieron un nuevo cierre que se prolongó hasta el curso siguiente y que supuso la pérdida de matrícula para 8.00o estudiantes ${ }^{42}$. Las

${ }^{41}$ Sobre las huelgas del inicio del segundo trimestre del curso 1974-1975, véase EQUipo LímiTe (Georgina Cisquella, José Luis Erviti, Maite Goicoechea, José Luis Gómez Mompart y José A. Sorolla): La agonía de la Universidad franquista, Barcelona, Laia, 1976, pp. 68-123.

${ }_{42}$ El cierre de las Facultades de Derecho, Filosofía y Letras, Medicina y Ciencia de Valladolid, en Díez Abad, María del Rosario: «La lucha por la democracia: los estudiantes del PCE frente al cierre de la Universidad de Valladolid decretado por el gobierno franquista en febrero de 1975", 
jornadas de lucha y las huelgas se extendieron a casi todas las universidades entre los días i9 (cuando la de Salamanca fue cerrada) y 26 de febrero, con secuela de encierros, manifestaciones, asambleas, concentraciones y marchas que coincidieron con el desarrollo de la huelga nacional de $\mathrm{PNN}^{43}$. La huelga general motivada por la clausura de la Universidad de Valladolid fue el momento culminante de la lucha estudiantil en esos años postreros del régimen. No fueron los centros, sino los consejos de distrito y las asambleas estatales las que dirigieron el movimiento, pero estas instancias participativas desaparecieron con la vuelta a clase, huérfanas de un apoyo continuado por parte de la comunidad escolar. Los comités de curso y las organizaciones de extrema izquierda perdieron definitivamente el liderazgo en 1974-I975, y el movimiento estudiantil lo pasó a controlar la Junta Democrática de España y los partidos y sindicatos que la formaban: PCE, Partido Socialista Popular (PSP), CC. OO., etc.

La última gran batalla del movimiento estudiantil tuvo lugar entre diciembre de 1975 y marzo de 1976, con la mira puesta en el derrocamiento del régimen mediante la ruptura democrática preconizada por la Junta Democrática animada por el PCE y la JGR, que eran los grupos con mayor capacidad de movilización en las aulas, y que fueron los que llevaron la voz cantante en el periodo de más intensa lucha para impedir el continuismo del régimen, en conexión con el sindicalismo obrero. En la primavera de 1976 se produjeron las primeras protestas universitarias después de la muerte de Franco. El 4 de marzo, los estudiantes y los PNN protagonizaron manifestaciones en Madrid, Valencia, Málaga, Salamanca y Zaragoza, para acabar con la precariedad laboral del profesorado. La virtual desaparición del movimiento estudiantil en junio de ese año -fenómeno al que contribuyó decisivamente el abandono que sufrió de mano de los partidos políticos más significados- coincidió en el caso del PCE con la práctica desorganización de sus potentes organizaciones estudiantiles. De ahí su proposición, a partir de 1977, de un bloque universitario que debían constituir los profesores numerarios, los PNN y los alumnos para propiciar el establecimiento de la democracia en la Universidad ${ }^{44}$.

El movimiento estudiantil luchó intensamente por la imposición de una alternativa democrática entre 1975 y 1978 , pero los partidos rupturistas perdieron influencia a partir de la Ley de Reforma Política de 1977, que marcó el principio del fin de la estrategia antifranquista de confrontación y el inicio de la etapa negociadora que caracterizaría la política de consenso. El nuevo marco de libertades, ratificado en la Constitución de 1978, supuso un cambio sustancial en los modos

en Bueno, Manuel; Hinojosa, José y García, Carmen (coords.): op. cit. Véase también «Valladolid: los límites de Esteruelas», Vanguardia. Portavoz de la Organización Universitaria de Madrid del PC, I. ${ }^{a}$ quincena mayo 1975, p. 5.

43 Sobre el movimiento de los PNN entre 1972 y 1975, véase EQuipo Límite: op. cit., pp. II5-II6.

44 La crisis del PCE, en UGALDE, Pablo: «El movimiento estudiantil y la izquierda», Zona Abierta, 25 (mayo-junio 1980), p. 44. Su propuesta «bloquista» en el folleto «PCE. Resoluciones de la primera conferencia de la organización universitaria de Madrid» (II-I977), p. IO, en AH.PCE, Fuerzas de la Cultura, caja I23. 
de la protesta escolar (reuniones, manifestaciones, huelgas...) y en el alcance de las mismas. A pesar del fracaso de su utopía revolucionaria, las aulas fueron uno de los grandes laboratorios culturales de la transición democrática, en sus aspectos de ruptura generacional, de capacidad de movilización y de persistencia durante años, hasta el punto de constituir una eficaz escuela de aprendizaje político y de inculcación de valores cívicos sobre el conjunto de la sociedad ${ }^{45}$. Como muestra de su trascendencia, en los SDEU se formó y militó toda una generación de líderes que siguió teniendo una enorme influencia en la política española hasta fines de siglo $\mathrm{xx}$.

\section{Los derroteros de la protesta estudiantil durante la transición: la movilización contra la LAU (1979-1980)}

Se ha dicho que el movimiento estudiantil fue el «gran perdedor» de la transición, ya que la conquista de la democracia se saldó con su propia disgregación. Con todo, siguió protagonizando importantes acciones de protesta durante la transición, como la respuesta al Estatuto de Centros Docentes y la Ley de Autonomía Universitaria (LAU) impulsados por la UCD en el otoño de 1979, por medio de paros orquestados por una Coordinadora Estatal de Universidades. La protesta anti-LAU, que se desarrolló durante el curso 1979-1980, coincidió con una ralentización del proceso de reforma política, el incremento de la conflictividad sociolaboral tras la promulgación del Estatuto de los Trabajadores y el empeoramiento de las expectativas laborales por el aumento del paro. Centenares de miles de estudiantes de enseñanza media y, en menor medida, de educación superior, salieron a la calle en la protesta escolar más multitudinaria de la historia de España, en la que la corporación escolar actuó una vez más como movimiento social y como grupo de presión académico y corporativo. Fue la última gran movilización escolar del postfranquismo. La fase de preparación de la protesta se había desarrollado desde octubre a inicios de diciembre en las universidades de Santiago, Oviedo, Valencia, Salamanca y, sobre todo, Madrid, donde el movimiento de protesta fue impulsado desde la Facultad de Filosofía y Letras de la Autónoma, a iniciativa de militantes de distintos partidos. Los estudiantes convocaron varios paros los días 21 y 29 de noviembre (en que la Policía hirió a varios estudiantes en Santiago) y 5 (con participación de 80.000 estudiantes en Madrid), 6 y 7 de diciembre. El momento álgido de la acción reivindicativa se produjo el i3 de diciembre: ese día, la huelga fue casi total en los institutos de Bachillerato y en las facultades. Después de que, por la mañana, más de roo.00o estudiantes participasen en la manifestación de Madrid, por la tarde miles de escolares acudieron a la multitudinaria marcha organizada por Cc. Oo. en contra del Estatuto de los Trabajadores y en apoyo de los obreros de Chrysler-Talbot. Pero en el momento

45 Carrillo-Linares, Alberto: «Movimiento estudiantil antifranquista, cultura política y transición política a la democracia», Pasado y Memoria, 5 (2006), pp. 167-I68. 
en que otra manifestación estudiantil paralela, convocada a la misma hora, trató de unirse a la primera, que estaba comenzando a disolverse, la Policía cargó brutalmente, disparando con munición real, abatiendo en la Ronda de Valencia a los estudiantes José Luis Montañés Gil y Emilio Martínez e hiriendo a varios más ${ }^{46}$. Al día siguiente tuvieron lugar manifestaciones estudiantiles en todo el Estado para protestar contra los asesinatos y los detenidos, y se anunciaron paros en numerosas empresas.

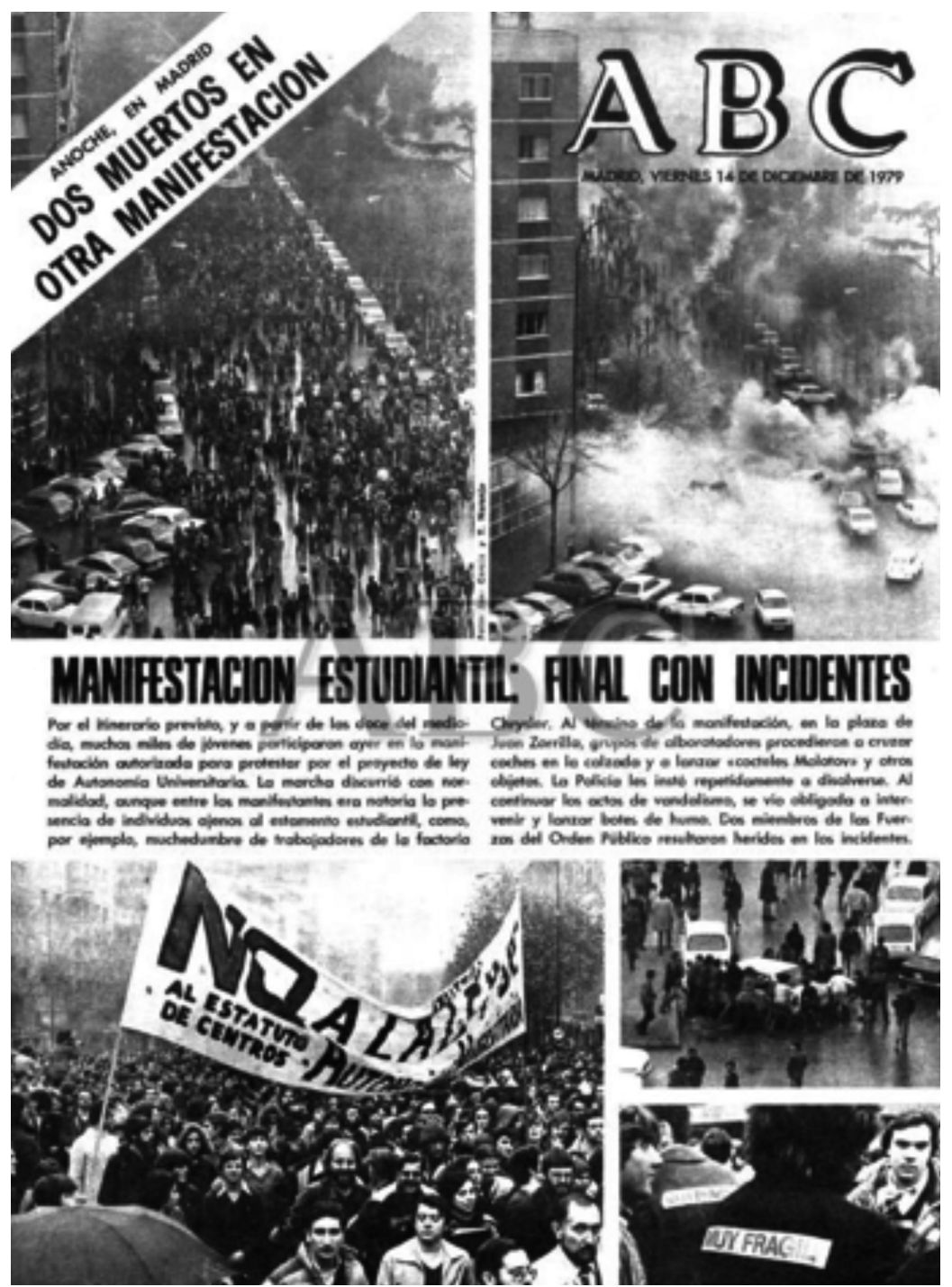

46 Soutullo, Daniel; Celada, Juan y García, Yolanda: Un curso de lucha estudiantil, Madrid, Revolución, 1980, pp. 54-57. 
Tras la celebración en Valencia de una Reunión General de Universidades los días is y i6 de diciembre, todos los distritos se organizaron en coordinadoras de enseñanza superior y media, y plantearon jornadas de protesta para los días i7 y I8 de diciembre, además de una semana de lucha que habría de culminar en una huelga general para la semana del 28 de enero al 3 de febrero de i980. Tras la reunión en la capital el 19 y 20 de enero de una Coordinadora Estatal del Movimiento Universitario, el día 3I unas 20.000 personas, en su gran mayoría estudiantes convocados por las coordinadoras de Universidad e INB y FP se manifestaron en el centro de Madrid durante dos horas contra la LAU, el Estatuto de Centros Docentes y la Ley de Financiación de la Enseñanza. La marcha partió de la plaza de Castilla sin apenas incidentes, aunque en diversos momentos se recordó a los dos jóvenes muertos por la Policía el i3 de diciembre con gritos de «No estamos todos, faltan los muertos», «Policía, asesina» y «Fuerza Nueva, asesina». Las peticiones de los congregados se realizaron al ritmo de palmas y pasos de baile bajo las consignas «UCD, UCD, la sotana se te ve», «La ley de autonomía es una porquería», "Con el Estatuto haremos un canuto", y alusiones jocosas a los ministros de Educación y Universidades: «Otero, gorrino, trabaja de interino», «Seara, capullo, la ley es un chanchullo», «Seara, Seara, tienes mucha cara» y «Un bote, dos botes, Seara el que no bote». Entre el duelo y la fiesta, los estudiantes reivindicaban una enseñanza popular y gratuita, la gestión democrática de los centros y la «Escuela para todos, trabajo para todos». También se dirigieron recomendaciones a los partidos de la izquierda parlamentaria: «PSOE, PCE, no pactéis». A las 21:30, al llegar los últimos grupos a la glorieta de Cuatro Caminos, lugar previsto para el final de la manifestación, la Policía Nacional cargó violentamente contra los concentrados en el metro y los cafés colindantes a la plaza, acosando y agrediendo a varios periodistas. A partir de las diez de la noche, pequeños grupos de jóvenes protagonizaron «saltos» en diferentes lugares de la capital, que en ocasiones provocaron cortes de tráfico. En zonas cercanas a Cuatro Caminos fueron arrojados a la calzada bancos, papeleras, bolsas de basura y otros objetos. La Policía practicó una veintena de detenciones durante estos incidentes ${ }^{47}$.

Coincidiendo con el declive de la movilización anti-LAU, la joven estudiante de Fp Yolanda González, miembro de la Coordinadora de Enseñanza Media de Madrid y militante del PST, fue secuestrada y asesinada el 2 de febrero por un grupo armado vinculado al partido ultraderechista Fuerza Nueva ${ }^{48}$. La Coordinadora Estatal de Universidades decidió convocar una «jornada antifascista» para el I8 de febrero. En la huelga subsiguiente, realizada bajo amenazas de la ultraderecha, participaron 800.000 estudiantes, el $60 \%$ de los profesores de Bachillerato, los profesores interinos despedidos, la Federación de Enseñanza de Cc. oo. y otros sindicatos del sector educativo. Esta jornada marcó el ocaso del movimiento, afectado por la cercanía de los exámenes y el cansancio de la lucha. Tras una marcha a Madrid de 5.000 estudiantes el i y 2 de marzo que acabó a la puerta de las

47 El País, I-II-1980.

${ }_{48}$ Soutullo, Daniel; Celada, Juan y García, Yolanda: op. cit., pp. 73-76. 
Cortes, se produjo un claro reflujo de la actividad reivindicativa, que había tenido un fuerte contenido político anticapitalista, antifascista, antirrepresivo, antieclesiástico y, en cierta medida, antimilitarista y feminista ${ }^{49}$. La movilización, que había afectado a 23 provincias, mezcló rasgos de protesta corporativa y política. Su vocación unitaria, impuesta por la dinámica asamblearia desde la base y por la naturaleza de las reivindicaciones (reforma educativa, medidas contra la represión policial y el fascismo, etc.), fue un rasgo de continuidad con el movimiento antifranquista de la década anterior. La fuerte desconfianza manifestada en las asambleas respecto de los partidos y de los posibles manejos antidemocráticos de sus representantes fomentó el burocratismo, a pesar de que se exigió en vano una participación activa de los estudiantes en la elaboración de la LAU.

\section{La continuidad de la protesta estudiantil en la etapa de consolidación democrática: las movilizaciones contra la LRU, la LOU, el Plan Bolonia y la Ley Wert (198I-20I7)}

A inicios de los años ochenta se acentuó el sentimiento de desencanto político entre los sectores de menor edad. En una encuesta realizada en 1980, solo un $26 \%$ de los jóvenes pensaba que la democracia iba a resolver los problemas del país, un $33 \%$ opinaba que iba a seguir igual y un $25 \%$ que evolucionaría a peor ${ }^{5}$. Con todo, un $57 \%$ de los encuestados se situaba en 1982 dentro de posiciones de izquierda, el $33 \%$ de ellos en el PSOE ${ }^{5 \mathrm{~s}}$. La despolitización de la protesta escolar no solo se explica por el desencanto ideológico propio de la época o por la existencia de nuevos canales y formas de expresión de las reivindicaciones sectoriales. La normalización política restó atractivo a una movilización sectorial que solo podía discurrir por cauces reformistas.

La victoria del PSOE en 1982 produjo un rápido eclipse de la izquierda radical en ámbitos como el universitario. La aprobación de la Ley Orgánica II/83, de 25 de agosto, de Reforma Universitaria (LRU), que se mantuvo en vigor hasta el I3 de enero de 2002, generó grandes expectativas de mejora y rompió la unidad del movimiento estudiantil. La LRU establecía una representación estudiantil por centros universitarios, lo cual favoreció la tendencia a formar agrupaciones escolares de ámbito cada vez más reducido. La protesta contra la LRU se inició por asuntos estrictamente universitarios como el incremento de las tasas, la imposición de los numerus clausus, el problema de los no admitidos, la selectividad, la reducción de

49 Déniz Ramírez, Francisco Antonio: op. cit., p. 267.

so Vaquero, Carlos: «Movimiento estudiantil y cambios políticos en la España actual. La influencia del cambio de época en la acción colectiva estudiantil», en Román Marugán, Paloma y Ferri Durá, Jaime (eds.): Los movimientos sociales. Conciencia y acción de una sociedad politizada, Madrid, Consejo de la Juventud de España, 2002, p. I2I.

si Martín Serrano, Manuel (dir.) [con la colaboración de Begoña Cerezo Mata y María José Aguilera Arilla]: Los universitarios madrileños. Vida, afanes y creencias después de la Dictadura, Madrid, Dirección General de la Juventud, 1982, p. 283. 
los presupuestos y la escasez de becas, a los que se añadió la reivindicación de una mayor representatividad del alumnado en el Claustro Universitario, en las Juntas de Centro y en la elaboración de los planes de estudio. Entre el 26 de febrero y el 3 de marzo de 1984 transcurrió una «semana de lucha» en la que, según los convocantes, se manifestaron 300.000 estudiantes en toda España. El 4 de diciembre se produjeron nuevas protestas masivas, en las que descolló una huelga general anunciada por una coordinadora creada por los estudiantes que formaban parte de los claustros universitarios. Según la prensa de entonces, el paro, apoyado por los PNN, tuvo «un alto nivel de participación», ya que 26 universidades secundaron la protesta y 10.000 estudiantes participaron en la ulterior manifestación celebrada en Madrid. Las movilizaciones incluyeron encierros en las facultades, simbólicas «voladuras» de los edificios (como ocurrió en el de Ciencias de la Información de Madrid) y manifestaciones que, en ocasiones, acabaron «sitiando» a las autoridades académicas (como sufrió el rector de la Complutense, Amador Schüller) hasta la llegada de la Policía. El debate sobre la LRU se planteó con particular intensidad hasta 1985 a nivel de facultad, a través de asociaciones, plataformas y colectivos con vocación unitaria que realizaban actividades reivindicativas de orden cultural, político, social, institucional o específico, y se coordinaban con el resto de los centros y con otros grupos o redes fuera del ámbito universitario. La diversificación en su proyección institucional facilitó su coordinación con otros movimientos sociales ya maduros, como los colectivos anti-OTAN, antimilitaristas, pacifistas, feministas, vecinales, ecologistas, de solidaridad internacional, etc., duchos en participaciones asamblearias y contrarios a la creación de organismos de coordinación a nivel estatal.

A comienzos del curso 1986-1987 se filtraron a la prensa varias medidas ministeriales que afectaban, por un lado, a las enseñanzas medias (los nuevos estatutos de régimen interno y la anulación de exámenes de septiembre) y, por otro, a la Universidad en su reforma de planes de estudio. También, como todos los años, se formaron asambleas de no admitidos. Fue entonces cuando el movimiento estudiantil cobró nuevo impulso, aunque en esta ocasión la base del movimiento estuvo en los INB, desde donde se orquestó una huelga de asistencia a clases y exámenes que duró casi tres meses, mientras que en las universidades la agitación comenzó en enero y se prolongó hasta mayo. Pronto aparecieron coordinadoras en casi todas las provincias, sobre la base del tradicional asambleísmo estudiantil, aunque las organizaciones de estudiantes quedaron desbordadas por este movimiento que cosechó un eco muy desigual en las distintas comunidades autónomas.

Del Sindicato de Estudiantes salió la primera convocatoria de paro el 4 de diciembre de 1986, que arrojó un balance de 300.000 huelguistas en toda España, de ellos 250.000 en Madrid, que hicieron públicas reivindicaciones ligadas a la supresión de la selectividad y de los numerus clausus, la congelación de tasas y el aumento de becas y del presupuesto público de educación. La protesta se enconó por la brutal actuación de la Policía y por la actitud escasamente receptiva del ministro José María Maravall, que recibió a una comisión de estudiantes sin lograr parar la huelga. El día I7, más de un millón de estudiantes de los institutos de BUP 
y FP (en su mayoría chicos de I4-I8 años, primerizos en manifestaciones) decidió salir a la calle. A partir del 28 de enero de 1987 se entró en la fase de negociación, pero el Sindicato de Estudiantes anunció una nueva huelga para los días 20 al 23 de ese mes. Ese último día, el Sindicato y la Coordinadora de Estudiantes convocaron manifestaciones conjuntas en toda España. En la de Madrid, organizada por una coordinadora formada por miembros de la Unión de Juventudes Comunistas de España (UJCE) y los Colectivos de Jóvenes Comunistas (CJC) con el apoyo de las Juventudes Socialistas, a la que se incorporaron también miembros del estalinista Movimiento Comunista de España (MCE) y del trotskista Partido Obrero Socialista Internacionalista (POSI), unos grupos marginales perturbaron la marcha con el objeto de «montar la bronca y dar leña», utilizando tirachinas «mataelefantes» comprados en El Rastro, agrediendo a fotógrafos y cámaras de televisión y destrozando el mobiliario urbano, como reflejó la conducta anticívica de Jon Manteca frente al Ministerio de Educación. En los enfrentamientos, la Policía hirió de bala a la estudiante de I4 años María Luisa Prada.

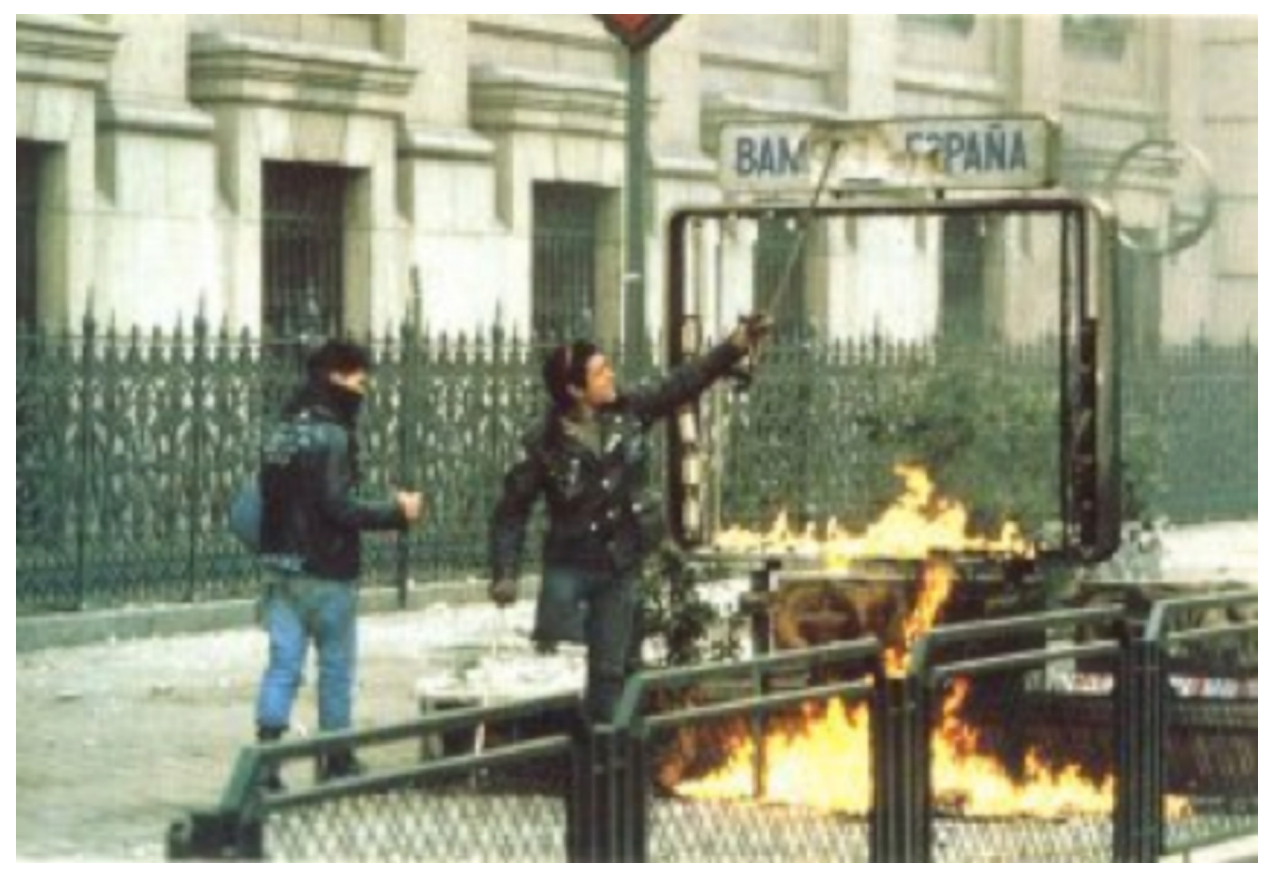

Madrid, 23-I-I987.

Los universitarios comenzaron a hacer su aparición a partir de febrero de 1987 , relevando a los estudiantes de enseñanza media en relación con las reformas de los planes de estudio y la selectividad. El Gobierno no autorizó la manifestación estudiantil convocada ante el Palacio de la Moncloa el día 6 de febrero, pero la segunda semana del mes marcó el momento culminante de la lucha: la huelga 
general se extendió a los universitarios y a las asociaciones de padres, profesores y trabajadores. El bloque anti-LRU de 1986-1987 recogió el grueso de las redes informales creadas en las universidades de Galicia, País Vasco, Canarias y Cataluña en oposición a la LAU y al Estatuto de Centros Docentes de 1979-1980, pero hubo de enfrentarse a otra tendencia del movimiento estudiantil, influida por el PSOE y el PCE, partidaria de favorecer una lectura progresista de la Ley y potenciar el trabajo institucional en el ámbito académico. Las movilizaciones estudiantiles de 1986-1987 no deben explicarse únicamente por las discrepancias respecto a la política educativa del Gobierno socialista, sino también por la frustración juvenil dirigida contra un poder controlado por la generación anterior, precisamente la que había impulsado los conflictos escolares de fines de los cincuenta y la década de los sesenta, que mantuvo el suficiente impulso político como para mantenerse en el poder hasta mediados de los años noventa ${ }^{s^{2}}$.

Tras la campaña en defensa de una Universidad pública de calidad en 1986-1987, el movimiento estudiantil continuó reaccionando en contra de las normas que le afectaban, como la Ley de Ordenación del Sistema Educativo (LOGSE) de octubre de 1990 o la subida de tasas y la reducción de las becas en octubre-noviembre de 1993. El cansancio del movimiento asambleario y la renuncia voluntaria del derecho a votar para elegir representantes mostraban que el compromiso social y político de los jóvenes ya no se desplegaba a través de los cauces tradicionales de partidos, sindicatos o asociaciones, sino en espacios informales vinculados a los Nuevos Movimientos Sociales (NMs) y a las Organizaciones No Gubernamentales (ONG).

Con el ascenso al poder del pp, el estudiantado pasó a oscilar entre la astenia derivada de la marginación de los trayectos más valorizables de los currícula y el estrés suscitado por una feroz competitividad por el acceso a los centros, másteres y estudios de mayor prestigio que podrían garantizar mejor su inserción laborals's. Tras la convocatoria de nuevas manifestaciones estudiantiles contra la subida de tasas en 1997 , la siguiente oleada de protestas mantuvo el mismo patrón de comportamiento que las anteriores, esta vez contra un Gobierno conservador anclado desde abril del 2000 en la prepotencia que le brindaba la mayoría absoluta en el Parlamento. El 7 de noviembre de 200 i se declaró una huelga general en la Universidad contra el Proyecto de Ley Orgánica de Universidades (LOU), que fue aprobada en el Congreso el 20 de diciembre. La protesta estudiantil que se desplegó a partir de entonces fue un movimiento descentralizado, en el que los sindicatos estudiantiles a nivel estatal perdieron protagonismo frente a las organizaciones locales y a las dinámicas asamblearias, ya que la agitación escolar estaba inserta en un ciclo de movilizaciones de escala global y mostró un repertorio de

${ }_{52}$ Álvarez Junco, José: «Movimientos sociales en España: del modelo tradicional a la modernidad postfranquista», en LARAÑa, Enrique y Gusfield, Joseph (eds.): Los nuevos movimientos sociales. De la ideología a la identidad, Madrid, cIs, I994, p. 437.

53 Rodríguez López, Emmanuel: «La Universidad y su crítica: movimiento estudiantil, reforma universitaria y mercado de trabajo (1975-2003)", Logos: Anales del Seminario de Metafísica, 36 (2003), p. 62. 
protesta acorde con esa descentralización, en el que los pequeños grupos asumieron el protagonismo y actuaron de forma novedosa proponiendo acciones distintas de carácter performativo, lúdico y festivo ${ }^{54}$. La adopción de estas formas innovadoras de movilización tuvo en la comunidad autónoma gallega un importante peso, tanto en relación al número de personas movilizadas como a la extensión, intensidad y eficacia de las mismas. Los repertorios de acción colectiva llamaron mucho la atención por su desbordada imaginación. Fue una campaña de protesta altamente teatral y artística, en la que acciones más clásicas (manifestaciones, concentraciones, encierros, cortes de tráfico, mesas informativas, huelgas absentistas, a «la japonesa» o de consumo) alternaron con sentadas, boicots a empresas e instituciones (concentraciones ante el INEM para apuntarse al paro, formación de colas ante las ventanillas de los bancos), y con actuaciones descentralizadas y no masificadas mucho más novedosas, que se desplegaron a través de hechos performativos sencillos, pero con una visibilidad notable y sin generar apenas conflicto: las cadenas humanas, los cacerolazos, los rezos en la catedral, los velatorios y el entierro carnavalesco de la Universidad, las acampadas salvajes, las donaciones de sangre, las clases en la calle, las acciones nudistas, las manifestaciones artísticas, la ostentación de lazos amarillos, la parodia de un mitin del PP en favor de la LOU en la plaza del Obradoiro o la impresión de lemas «no a la LOU» en billetes de banco fueron parte de este repertorio de protesta que intentó trasladar a la ciudadanía la idea de la defensa de la enseñanza pública ante el avance del plan privatizador del Gobierno"s.

El medio centenar de organizaciones escolares de toda España que habían constituido la campaña estatal contra la LOU y los sindicatos CC. OO. y UGT convocaron nuevas huelgas el 7 y I4 de noviembre ${ }^{56}$ que culminaron en un paro general de estudiantes el sábado I de diciembre de 20oI, cuyo desarrollo culminó con la marcha de entre 350.000 y 500.000 estudiantes, profesores y personal universitario por las calles de la capital. Más de 200.000 estudiantes se manifestaron en 53 ciudades $^{57}$. El 7 de marzo y el 29 de octubre de 2002 se repitieron las movilizaciones contra la Ley de Calidad de la Enseñanza, pero para ese entonces ya no se podía hablar de un movimiento estudiantil bien vertebrado.

El movimiento estudiantil tuvo una destacada participación en otras manifestaciones no estrictamente escolares, como las desarrolladas en contra del «decretazo» (huelga general de 20 de junio de 2002), contra la gestión gubernamental de la catástrofe ecológica producida por el vertido del petrolero Prestige o en

54 Ramos Martínez, Iván Julio: «La protesta estudiantil en Galicia contra la Ley Orgánica de Universidades», Athenea Digital: Revista de Pensamiento e Investigación Social, ro (2006), p. 3 [http://antalya.uab.es/athenea/numio/ramos.pdf].

" Llusia, M.: «El movimiento estudiantil gallego: asambleario, masivo y abierto a la sociedad», Página Abierta, I2I-I22 (diciembre 200I-enero 2002) y RAmos MARTíneZ: art. cit., p. 8.

${ }_{56}$ Simón, Pedro: «Más de I40.000 estudiantes protestan en 70 ciudades contra la ley universitaria. La de Madrid, con más de 50.000 asistentes, fue la mayor manifestación estudiantil de los últimos I5 años», El Mundo, I5-XI-200I, p. 7.

57 Pérez de Pablos, Susana: «Movilizaciones contra la Ley de Universidades. La mayor protesta universitaria de la democracia», El País, I5-XI-200I, p. 36. 
la protesta a escala global que se realizó en contra de la intervención armada en Irak el is de febrero de 2003. El 5 de marzo siguiente tuvo lugar una huelga general internacional de estudiantes contra la guerra, convocada por la Coalición de Jóvenes y Estudiantes por la Paz, y una nueva manifestación multitudinaria celebrada diez días más tarde convocó a 500.000 personas en Barcelona y Madrid. Tras el inicio de la guerra se produjo una nueva manifestación multitudinaria en la capital el día 22 de marzo.

El I3 de noviembre de 2008 tuvo lugar una protesta concertada de estudiantes de enseñanza secundaria y superior en sesenta ciudades, en contra de la privatización y la mercantilización de los estudios que creían implícitas en este programa de reformas, que por ende imponía un acortamiento de la mayoría de las licenciaturas. Además de 10.000 manifestantes en Madrid y de 17.000 en Barcelona, hubo concentraciones importantes en Valencia, Sevilla, Santiago y Granada ${ }^{88}$. El fin de semana del 22 al 23 de noviembre, la Policía irrumpió violentamente en un encierro en la Facultad de Geografía e Historia de Valencia, y el 24 un centenar y medio de estudiantes ocuparon la Facultad de Letras de la Autónoma de Barcelona, instalándose con sacos de dormir en el vestíbulo con la exigencia de la concertación de un Pacto Nacional para la Educación Superior. Esa semana, las protestas contra Bolonia también derivaron en la Complutense en encierros indefinidos en la Facultad de Ciencias de la Información, y en ocupaciones semanales en las de Filosofía Letras y Bellas Artes. Desbordados por los acontecimientos, los rectores advirtieron al Gobierno en una carta confidencial que la protesta «anti-Bolonia» no era pasajera, sino que el movimiento asambleario, vertebrado a nivel de facultad y de universidad, había alcanzado una dimensión estatal gracias al empleo del correo electrónico y de otras redes sociales, y amenazaba con recrudecerse en las Universidades Central y Autónoma de Barcelona, la Complutense de Madrid, Sevilla y Valencia. En cada facultad, asambleas abiertas de alumnos formaron grupos de trabajo y comisiones de comunicación, financiación, estudio de documentos y redacción de textos. El trabajo se canalizaba en los grupos de coordinación establecidos entre las asambleas, cuya información se exponía en una única página web a escala estatal. En ese momento, las actuaciones más secundadas eran las mesas informativas, las concentraciones a las puertas de los centros, las acampadas en los campus, las asambleas, las cadenas humanas de protesta, los encierros y los cortes de vías de comunicación, en una estrategia similar a la iniciada durante el curso anterior en Madrid`s.

Se pudo constatar la presencia de estudiantes en las acampadas del $15-\mathrm{M}$ de 20II, que posibilitaron la aparición de la Marea Verde en defensa de la Educación Pública. Tras la victoria electoral del PP en noviembre de 201 y el anuncio por parte del ministro de Educación José Ignacio Wert de que los recortes efectuados en la Comunidad de Madrid y en Cataluña se generalizarían y profundizarían a

$\$ 8$ «Miles de estudiantes contra la reforma universitaria», El País, I4-XI-2008, p. 37.

59 «Los rectores afectados por las revueltas piden ayuda al Gobierno», El País, 27-XI-2008, p. 34 y Pérez de Pablos, Susana y Aunión, J. A.: «En el corazón de la protesta», El País Domingo, 7-XII-2008, pp. I-5. 
escala nacional y que se efectuaría un ajuste presupuestario de 3.000 millones de euros, todos los sindicatos nacionales del sector (ANPE, CC. OO., CSIF, UGT y STES) acordaron la convocatoria de una huelga general a la que por primera vez en la historia fueron llamados todos los niveles educativos y centros docentes del Estado en la fecha del is de febrero de 20I2. Ese día, la Policía cargó brutalmente contra los estudiantes de Secundaria de Valencia y detuvo a 4r personas, 6 de ellos menores. El lunes 20, el jefe superior de Policía de la ciudad, Antonio Moreno Piquer, calificó a estos escolares como «enemigos», desatando una oleada de indignación en toda España.

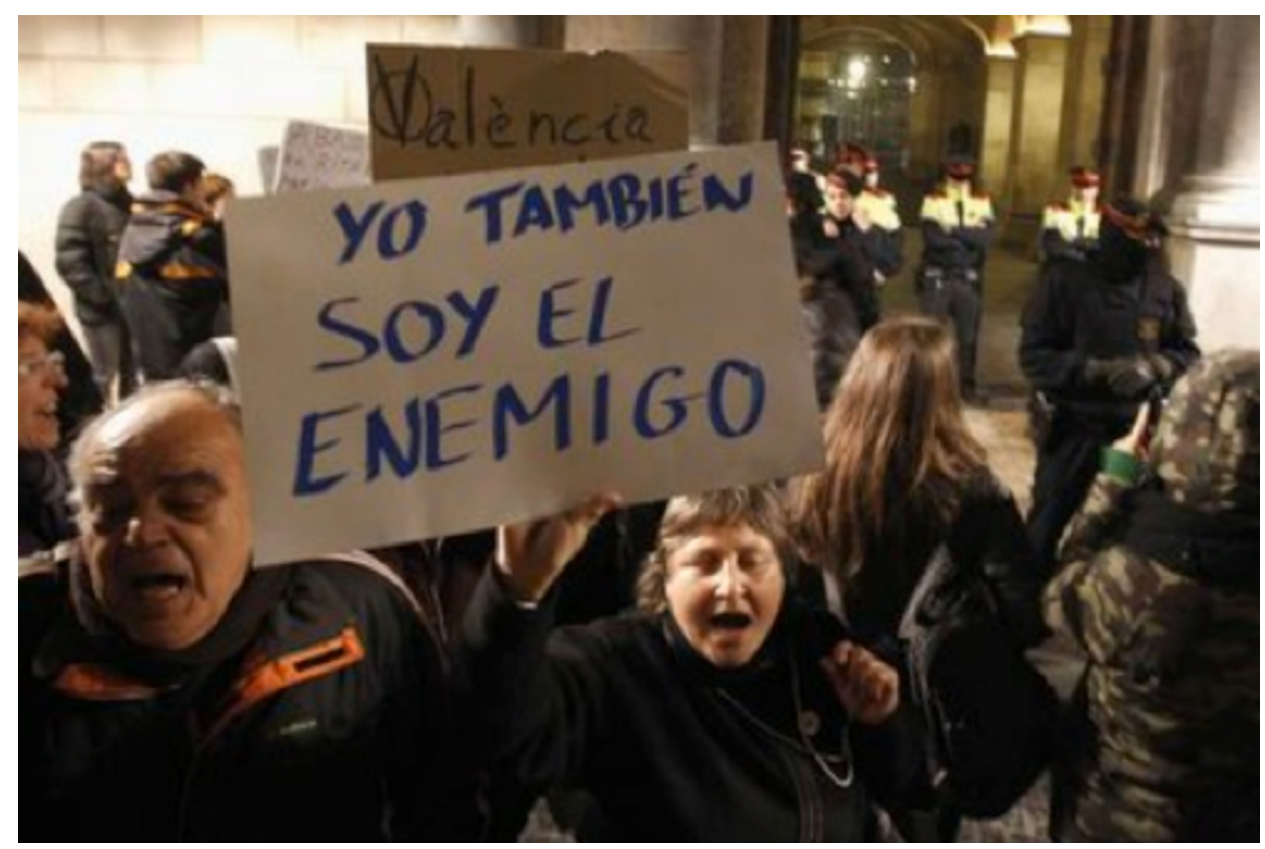

Manifestación de protesta en Barcelona, 2I-II-2OI2.

El 24 de octubre tuvo lugar un paro general en todos los niveles del sistema educativo con más éxito que la convocatoria de mayo de 2013. Después de que la Ley Orgánica 8/2013, de 9 de diciembre, para la mejora de la calidad educativa (LOMCE), se aprobase en el Congreso de los Diputados el 28 de noviembre de 20I3, se convocó una semana de lucha por parte de varios colectivos relacionados con la educación, como los sindicatos de los docentes, los alumnos, las asociaciones de padres o incluso la educación privada-concertada. Hasta la fecha, la última gran movilización estudiantil se ha efectuado contra el decreto de fines de febrero de 2015 que acorta las carreras universitarias. Unas 40.000 personas marcharon entre Atocha y Sol contra el conocido como decreto $3+2$. En la marcha se leían pancartas con lemas como «Pagadnos las becas con vuestras tarjetas» 0 «Franco ha Werto». 


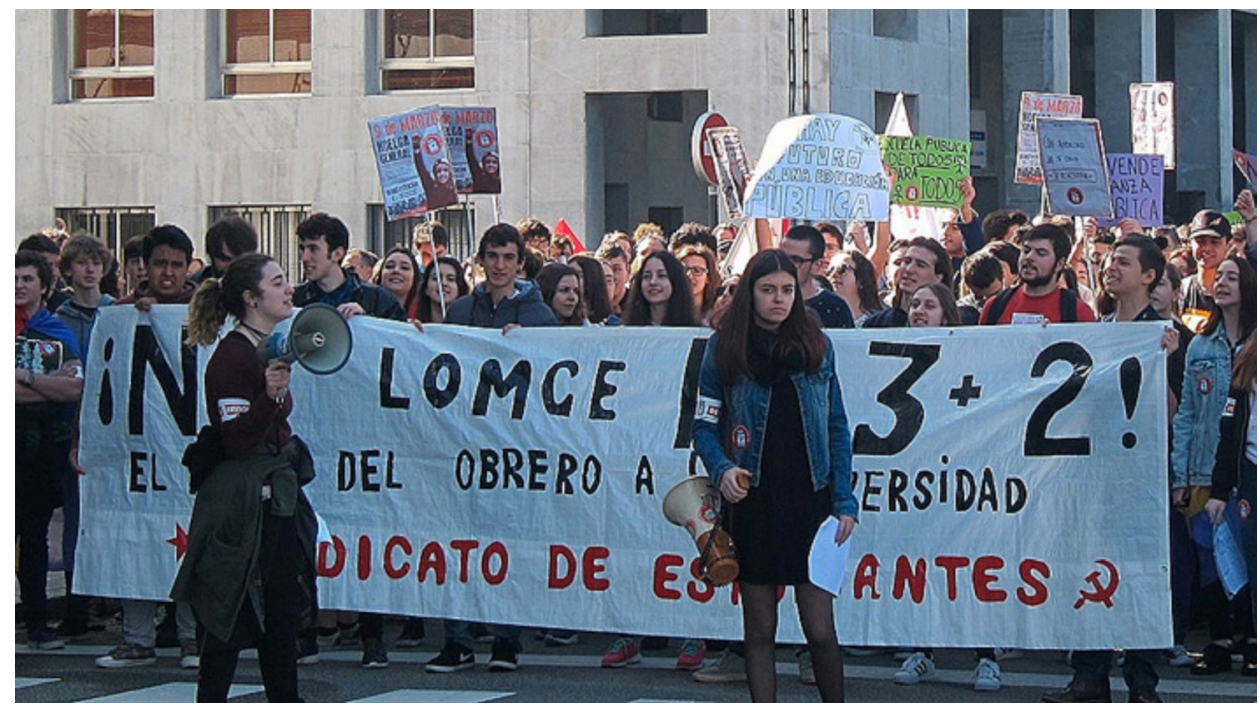

Manifestación estudiantil en Oviedo, 8-III-20I7.

\section{Conclusión: potencialidades y límites de la movilización estudiantil}

En su decurso cotidiano, la movilización escolar ha mostrado frecuentemente un carácter fragmentario. Ello se debe a varios factores, entre los que están el acelerado relevo generacional que se produce en las aulas, el ejercicio de una actividad profesional que se presume limitada en el tiempo o el hecho de que la comunidad universitaria esté formada por colectivos profesionales (estudiantes, catedráticos, profesorado numerario y no numerario, administrativos, etc.) con intereses no necesariamente coincidentes. A ese respecto, hay que destacar la influencia de la autoridad intelectual y moral del profesorado a la hora de liderar, canalizar o enconar la contestación. Desde la turba estudiantil al sindicato más o menos reconocido a nivel oficial, la interacción con el cuerpo de docentes resulta esencial, bien sea bajo la forma de hostilidad (caso del «troyanismo» o gamberrismo escolar superviviente hasta inicios del siglo xx), de adhesión a sus reivindicaciones (caso de la reacción corporativa de la FUE en la segunda mitad de los años veinte), de cooperación en vanguardia (caso de la movilización profesional de 1965) o de creciente desvinculación y autonomía (casos de la acción sindical más o menos reconocida en los años sesenta). En ocasiones, la relación con los partidos políticos mantiene esa misma dinámica entre el «seguidismo» y el «vanguardismo». En todo caso, la protesta estudiantil parece progresar cuando goza del apoyo de alguna élite adulta integrada en el sistema (intelectuales, profesores, políticos) y cuando no tiene verdadera competencia en el ámbito escolar. Pero también avanza cuando lucha contra la excesiva oficialización de alguna organización estudiantil que asume el monopolio de la representación escolar. 
En segundo lugar, el estudiantado actúa como una minoría privilegiada en un entorno frecuentemente cerrado a influencias externas. Ello hace que los escolares constituyan de hecho un colectivo automarginado física e intelectualmente, en el sentido de un elitismo minoritario y accidental, lo que no impide que, en ocasiones, las algaradas estudiantiles sean síntomas de un patente malestar político. Por otro lado, este mismo carácter selecto les hace menos vulnerables a la represión oficial que otros movimientos reivindicativos.

La proverbial discontinuidad de la protesta estudiantil es agudizada por el carácter frecuentemente estacional de la misma, que acostumbra a concentrarse en los días intermedios de la semana (el momento más lejano a la influencia familiar) y en los primeros meses del año, cuando el alumno llevaba un tiempo suficiente de asistencia a la universidad, había tomado conciencia de su situación y había forjado los lazos esenciales de su identidad de grupo. El reflujo acostumbraba a venir hacia mayo, en la proximidad de los exámenes finales. Por eso, como dice Álvarez Cobelas, la instauración de los exámenes parciales de febrero tuvo en su tiempo un designio evidentemente desmovilizador ${ }^{60}$, como también lo tuvo la separación de la Universidad del entorno urbano de la gran ciudad (caso de Madrid en los años veinte) o el experimento de las Universidades Autónomas en los años sesenta.

La fuerte pulsión generacional de la protesta estudiantil puede promover solidaridades intensas entre los individuos, pero también condicionar su acción futura. El hecho de que la experiencia universitaria «normal» abarque un periodo de 5-7 años condiciona gravemente la continuidad del movimiento escolar, como pudieron constatar los fundadores de la FUE a la altura de 1932-1933. Los testimonios de algunos alumnos especialmente implicados en la lucha antifranquista acortan aún más este plazo: se tenían dificultades para movilizar al primer curso (aún sin una clara identidad colectiva) y al último, cuyas preocupaciones derivaban hacia la inminente colocación profesional. El problema de la transmisión del sentimiento disidente entre generaciones ha sido y es una preocupación constante entre las fuerzas de oposición, y se trata de superar mediante un incremento de la militancia política y la construcción de una contracultura contestataria capaz de socializar con rapidez a las nuevas hornadas de estudiantes.

En todo caso, las circunstancias del entorno sociopolítico (por ejemplo, el grado de autonomía gestora de la Universidad, la mayor o menor vulnerabilidad del sistema a las protestas, la aceptación del pluralismo ideológico o la capacidad de cooptación profesional y política) son factores determinantes a la hora de brindar o arrebatar oportunidades de movilización a los estudiantes. Del mismo modo que esta misma capacidad de actuación siempre está íntimamente vinculada a su propia autopercepción como colectivo autónomo, ya fuera bajo la fisonomía de la comunidad de estudiantes, la corporación profesional, el sindicato o el movimiento juvenil politizado.

Durante la actual etapa democrática, los estudiantes se han movilizado contra los tres partidos que han asumido el gobierno: en 1979-1980 frente a UCD en contra de

${ }^{60}$ Álvarez Cobelas, José: op. cit., p. 195 . 
la LAU y del Estatuto de Centros Docentes; en 1986-1987 frente al PSOE contra la selectividad y en defensa de una Universidad pública de calidad, y en 1993-1994 en contra de las tasas; y en 200I-2002 frente al PP contra la Ley de Ordenación Universitaria (LOU), el Plan Bolonia o los actuales recortes en educación. El movimiento estudiantil ha tenido una destacada participación en otras manifestaciones no estrictamente escolares, como las desarrolladas en contra del «decretazo» (huelga general de 20 de junio de 2002), contra la gestión gubernamental de la catástrofe ecológica producida por el vertido del petrolero Prestige, la protesta a escala global que se realizó en contra de la intervención armada en Irak el is de febrero de 2003, la manifestación convocada por los blogs alternativos en protesta contra de la campaña de desinformación orquestada por el Gobierno Aznar en los días que mediaron entre los atentados yihadistas y la jornada electoral del I4-M y el reciente movimiento de los «Indignados» que tomó las calles y las plazas a partir del is de mayo de 201 .

Aún hoy, los estudiantes se siguen movilizando en muestra de hostilidad a la penetración de la filosofía empresarial en la universidad pública, como lo muestran las movilizaciones de los cursos 2007-2008 y 2008-2009 contra el diseño del Espacio Europeo de Educación Superior acordado en Bolonia en junio de 1999. El predomino actual de las protestas por razones académicas, profesionales o corporativas quizás sea el peaje obligado de una representación estudiantil que dispone ya de cauces normalizados de expresión en un contexto general de libertades públicas y autonomía universitaria. Su eventual politización (como en épocas anteriores) parece venir de la mano de su confluencia de intereses con otros colectivos de protesta en coyunturas especialmente propicias, como es la política de recortes en servicios sociales (y educativos) implementada por los gobiernos con la excusa de la crisis económica. Pero históricamente hablando, el talón de Aquiles del movimiento estudiantil español ha sido su débil coordinación con el resto de los movimientos sociales, especialmente los procedentes del ámbito laboral. Las etapas de agitación escolar de 1956, I962, I967-1968 y 1979-1980 coincidieron total o parcialmente con movilizaciones obreras, pero no llegaron a alcanzar una real confluencia de objetivos y vieron muy limitado su potencial transformador de la situación política. Sin embargo, en 1929-I93I la reivindicación escolar y la política coincidieron imperfectamente y dieron al traste con dos regímenes: la Dictadura primero y la Monarquía después.

En la actualidad, a pesar de su presencia ocasional en las protestas contra la Guerra del Golfo en I99I, los «indignados» y las acampadas del I5-M-20II o la Marea Verde entre 20II-20I2, el movimiento estudiantil sigue sin recuperar $-\mathrm{y}$ parece muy difícil que lo haga en un futuro inmediato- el singular protagonismo que tuvo como vanguardia del cambio democrático frente a las dos grandes dictaduras del siglo xx. Pero, para bien o para mal, el futuro nunca está escrito de antemano. 
